\title{
Epidural auditory event-related potentials in the rat to frequency and duration deviants: evidence of mismatch negativity?
}

\section{Tamo Nakamura 1,2,3, *, Patricia T. Michie ${ }^{1,2,3,4}$, William R. Fulham ${ }^{2,3,4,5}$, Juanita Todd ${ }^{1,2,3,4}$, Timothy W. Budd ${ }^{1,2,3,4}$, Ulrich Schall ${ }^{2,3,4,5}$, Michael Hunter ${ }^{1,2}$ and Deborah M. Hodgson ${ }^{1,2,3,4}$}

${ }^{1}$ School of Psychology, The University of Newcastle, Callaghan, NSW, Australia

${ }^{2}$ Priority Centre for Brain and Mental Health Research, The University of Newcastle, Callaghan, NSW, Australia

${ }^{3}$ Schizophrenia Research Institute, Darlinghurst, NSW, Australia

${ }^{4}$ Hunter Medical Research Institute, Newcastle, NSW, Australia

${ }^{5}$ School of Medicine and Public Health, The University of Newcastle, Callaghan, NSW, Australia

\section{Edited by:}

Micah M. Murray, Université de Lausanne, Switzerland

Reviewed by:

Christoph Kayser, Max Planck Institute for Biological Cybernetics, Germany

liro P. Jääskeläinen, University of Helsinki, Finland

*Correspondence:

Tamo Nakamura, School of Psychology, The University of Newcastle, University Drive, Callaghan, NSW 2308, Australia. e-mail: tamo.nakamura@newcastle. edu.au

\begin{abstract}
The capacity of the human brain to detect deviance in the acoustic environment preattentively is reflected in a brain event-related potential (ERP), mismatch negativity (MMN). MMN is observed in response to the presentation of rare oddball sounds that deviate from an otherwise regular pattern of frequent background standard sounds. While the primate and cat auditory cortex $(\mathrm{AC})$ exhibit MMN-like activity, it is unclear whether the rodent $\mathrm{AC}$ produces a deviant response that reflects deviance detection in a background of regularities evident in recent auditory stimulus history or differential adaptation of neuronal responses due to rarity of the deviant sound. We examined whether MMN-like activity occurs in epidural AC potentials in awake and anesthetized rats to high and low frequency and long and short duration deviant sounds. ERPs to deviants were compared with ERPs to common standards and also with ERPs to deviants when interspersed with many different standards to control for background regularity effects. High frequency (HF) and long duration deviant ERPs in the awake rat showed evidence of deviance detection, consisting of negative displacements of the deviant ERP relative to ERPs to both common standards and deviants with many standards. The HF deviant MMN-like response was also sensitive to the extent of regularity in recent acoustic stimulation. Anesthesia in contrast resulted in positive displacements of deviant ERPs. Our results suggest that epidural MMN-like potentials to HF sounds in awake rats encode deviance in an analogous manner to the human MMN, laying the foundation for animal models of disorders characterized by disrupted MMN generation, such as schizophrenia.
\end{abstract}

Keywords: mismatch negativity, deviance detection, adaptation, epidural, rat

\section{INTRODUCTION}

Reduced amplitude of the brain event-related potential (ERP), mismatch negativity (MMN), has been a consistent finding in patients with a diagnosis of a schizophrenia spectrum disorder (Michie, 2001) with a recent meta-analysis (Umbricht and Krljes, 2005) reporting an overall effect size of 0.99 . In humans, $M M N$ is observed in response to the presentation of rare oddball sounds that deviate from an otherwise regular pattern of background standard sounds and is commonly extracted by subtracting the standard from the deviant ERP. As May and Tiitinen (2010) note, MMN is therefore a response to stimulus change that is derived arithmetically by a simple subtraction procedure. MMN occurs in the absence of attention to the oddball sequence and has as a consequence often been characterized as an automatic or preattentive brain response (Näätänen, 1992). It has been observed for sound sequences containing any discriminable change in simple physical features of background regular sounds (simple invariance deviants), such as frequency, duration, intensity, or spatial location (Picton et al., 2000) as well as change in more complex background regularities, such as melodic contour of sounds pairs (Winkler, 2007).

A variety of neurophysiological mechanisms have been proposed as explanations of the brain's ability to detect change in the acoustic background and produce MMN to deviant sounds (see Garrido et al., 2009; May and Tiitinen, 2010; Garagnani and Pulvermüller, 2011 for recent reviews): release from tonic inhibition (Näätänen, 1990), short-term synaptic plasticity [referred to as the model adjustment hypothesis (Winkler et al., 1996)], differential adaptation (Jääskeläinen et al., 2004), and combinations of these mechanisms. For instance, to explain MMN to simple invariance deviants, May and colleagues (May et al., 1999; May and Tiitinen, 2010) as well as Garagnani and Pulvermüller (2011) propose a combination of adaptation and lateral inhibition whereas the predictive coding model of Garrido et al. (2009) incorporates both adaptation and model adjustment mechanisms. However, while each of these models propose different underlying mechanisms, 
Garagnani and Pulvermüller (2011) point out that each emphasize "the importance of short-term mechanisms acting upon, or being driven by, the most recent sensory input” (p. 170). An alternate view of $\mathrm{MMN}$ that offers a more cognitive level of explanation is that proposed by Näätänen et al. (2005) that MMN results from an automatic comparison process that detects a discrepancy between a novel event and the representation of the regularity of recent stimulation retained in sensory memory.

There is increasing interest in identifying MMN-like activity in rodents in order to advance research into the neurophysiological and neurochemical mechanisms underpinning MMN generation and provide opportunities for translational MMN research such as the development of animal models of schizophrenia (Bickel and Javitt, 2009). However, an integration of previous MMN research in rats is difficult due to methodological differences between studies. These include whether MMN-like activity is measured using single/multiunit activity (MUA) and evoked local field potentials (eLFPs; von der Behrens et al., 2009; Farley et al., 2010) or from epidural sites (see Table 1), and whether controls for the physical characteristics of standard and deviant stimuli and recent stimulus history have been implemented. Similarly, the use of anesthesia during recordings makes interpretation of results problematic since anesthetics alter the physiological properties of neural elements underlying MMN activity (Roger et al., 2009). Only two of the nine previous MMN studies using epidural recordings in the rat (see Table 1) used awake (unanesthetized) animals.

The aim of the present study is to provide a comprehensive assessment of epidural potentials to frequency and duration oddball deviants in the awake unrestrained rat as well as under anesthesia and to determine whether these responses exhibit an MMN-like pattern under appropriate control conditions.

Bearing in mind that MMN is an arithmetic comparison of ERPs to rare deviant and a frequent standard sounds, a major methodological concern for rodent MMN studies is to ensure that the design allows a clear distinction between at least two explanations of why the deviant response is different, namely, a differential adaptation explanation vs. an explanation based on the deviant sound violating regularities in recent stimulus history. Similar concerns have been raised with respect to stimulus-specific adaptation (SSA) phenomena evident in MUA and eLFP recordings from auditory cortex (Ulanovsky et al., 2003; Nelken and Ulanovsky, 2007; Taaseh et al., 2011). SSA is the specific decrease in the response to a frequent standard stimulus, which does not generalize to a different rare deviant stimulus. Although the term SSA emphasizes the adaptation of neural responses to repetition of sounds, as noted by Taaseh et al. (2011), a key aspect of SSA in the auditory system is the production of a large response to a rare deviant sound, that could be due either to the fact that the response to the deviant is not adapted because of its rare occurrence, that is, differential adaptation due to the rarity of the deviant, or because the deviant represents a change relative to the regularity created by repeating the standard sound, that is, deviance detection. Similar alternate possibilities are relevant to the interpretation of MMN-like activity in evoked epidural recordings in the rat.

A common solution implemented in previous rat studies that attempts to distinguish rarity from deviance detection explanations of MMN-like responses is inclusion of the deviantalone condition (see Table 1) in the design where intervals between successive deviants are the same as in the oddball sequence but no standards are presented (i.e., silence intervenes between successive deviants). However, while the deviant-alone condition controls for the interval between successive deviants (one index of rarity), it does not control for contributions from the deviant interrupting regularity in background stimulation. Therefore, a control condition is required where multiple different tones intervene between successive deviants so that there is no regularity in recent stimulation present. The "many standards" control condition first employed by Jacobsen and Schröger (2001) in the human literature meets these requirements and also controls for rarity: the deviant is presented at the same probability in the many-standards sequence as in the oddball sequence with constant or "common" standards. A number of animal studies have previously utilized this control condition in MUA and eLFP investigations of SSA (Ulanovsky et al., 2003; Farley et al., 2010; Taaseh et al., 2011) and in one very recent study of MMN in rat epidural recordings (Astikainen et al., 2011). An additional important issue for the interpretation of differences between the deviant and standard response in rodent epidural recordings is that any observed differences cannot be explained solely by the physical differences between sounds. This requires a design in which the roles of standards and deviants are reversed in oddball sequences (often called a flip-flop design) so standard and deviant ERPs are elicited by stimuli with identical physical characteristics. The many-standards control also allows a comparison between ERPs to oddball deviants and to sounds (referred to here as control deviants) with identical physical characteristics and probability of occurrence.

\section{MATERIALS AND METHODS SUBJECTS, SURGICAL PROCEDURES, AND ELECTROPHYSIOLOGICAL RECORDINGS}

The experiments were performed on seven Wistar rats (six males). The surgery was performed when the male animals were on average 182 days old (144-216 days old) and the female rat was 201 days old. The average weight of the male animals was $566.4 \mathrm{~g}$ (505.1$603.9 \mathrm{~g}$ ) on the day of surgery and the female rat $320.7 \mathrm{~g}$. This study was approved by the University of Newcastle Animal Care and Ethics Committee (A-2009-108) and all experiments conformed to the relevant regulatory standards.

Animals were anesthetized with fentanyl $(300 \mu \mathrm{g} / \mathrm{kg}$ i.p. $)$ and medetomidine $(300 \mu \mathrm{g} / \mathrm{kg}$ i.p.), and/or isoflurane and the rat placed on a heating pad during surgery. A battery operated biotelemetric radiotransmitter (model \# TA11CA-F40, Data Sciences International, St. Paul, MN, USA) was implanted in the peritoneal cavity. Insulated biopotential leads from the transmitter were passed subcutaneously to the base of the skull. The skin over the skull was exposed and two small burr holes were drilled in the skull, one hole for the active electrode over the right auditory cortex ( $4.5 \mathrm{~mm}$ posterior to the bregma and $3.5 \mathrm{~mm}$ lateral to the midline) and the other for the reference electrode in the left hemisphere $(2 \mathrm{~mm}$ posterior to the lambda and $2 \mathrm{~mm}$ lateral to the midline). These locations are based on previous research demonstrating MMN-like epidural responses in the rat (Tikhonravov et al., 2008). The leads were fixed with dental acrylic. Carprofen 
Table 1 | Summary of previously published papers on epidural mismatch negativity (MMN) potentials in rats showing details of animal state, location of recording sites, deviant feature, design control details, polarity of the MMN, and latency window of the effect.

\begin{tabular}{|c|c|c|c|c|c|c|}
\hline Author & $\begin{array}{l}\text { State: awake } \\
\text { vs. anesthesia }\end{array}$ & $\begin{array}{l}\text { Location of active and } \\
\text { reference sensors }\end{array}$ & $\begin{array}{l}\text { Deviant } \\
\text { feature }\end{array}$ & Design controls & $\begin{array}{l}\text { Polarity of MMN } \\
\text { response }\end{array}$ & $\begin{array}{l}\text { Window of } \\
\text { effect (ms) }\end{array}$ \\
\hline $\begin{array}{l}\text { Astikainen } \\
\text { et al. (2006) }\end{array}$ & Urethane & $\begin{array}{l}\text { Active sensor - same as reported } \\
\text { in Ruusuvirta et al. (1998). } \\
\text { Reference - over the nasal bone. }\end{array}$ & $\begin{array}{l}\text { Frequency, } \\
\text { frequency and } \\
\text { intensity } \\
\text { conjunctions }\end{array}$ & $\begin{array}{l}\text { Flip-flop design }{ }^{1} \text {; } \\
\text { frequency and intensity } \\
\text { conjunctions controlled } \\
\text { for adaptation effects }\end{array}$ & $+v e$ & 76-108 \\
\hline $\begin{array}{l}\text { Astikainen } \\
\text { et al. (2011) }\end{array}$ & Urethane & $\begin{array}{l}\text { Active sensor positioned on the } \\
\text { basis of response to tone stimuli } \\
\text { within a 4-mm } \times 4 \text {-mm exposed } \\
\text { region of dura over the auditory } \\
\text { cortex in the left hemisphere, } \\
4.5-6.5 \mathrm{~mm} \text { posterior to bregma } \\
\text { and } 3.0-5.0 \mathrm{~mm} \text { ventral to } \\
\text { bregma. Reference - positioned } \\
\text { over the right side of the brain } \\
\text { above the cerebellum (AP } \\
\text {-11.0 } \mathrm{mm}, \mathrm{ML} 3.0 \mathrm{~mm} \text { ). } \\
\text { Ground - positioned over the right } \\
\text { side of the brain above the frontal } \\
\text { cortex (AP }+4.0 \mathrm{~mm}, \mathrm{ML} 3.0 \mathrm{~mm} \text { ). }\end{array}$ & $\begin{array}{l}\text { Ascending and } \\
\text { descending } \\
\text { frequency }\end{array}$ & $\begin{array}{l}\text { Many-standards control } \\
\text { condition }\end{array}$ & $\begin{array}{l}\text { +ve but } \\
\text { significant only } \\
\text { for ascending } \\
\text { frequency } \\
\text { deviants }\end{array}$ & $60-100$ \\
\hline $\begin{array}{l}\text { Eriksson } \\
\text { and Villa } \\
\text { (2005) }\end{array}$ & $\begin{array}{l}\text { Awake; } \\
\text { ketamine and } \\
\text { xylazine } \\
\text { hydrochloride }\end{array}$ & $\begin{array}{l}\text { Multi-electrode arrays were } \\
\text { positioned bilaterally in the lower } \\
\text { cortical layers (IV-VI) in the core } \\
\text { auditory regions of the temporal } \\
\text { cortex }{ }^{2} \text {. } \\
\text { Reference - an epidural electrode } \\
\text { was positioned in the anterior part } \\
\text { of the skull. }\end{array}$ & $\begin{array}{l}\text { Synthetic } \\
\text { vowels with a } \\
\text { different } \\
\text { fundamental } \\
\text { and/or formant } \\
\text { frequencies }\end{array}$ & $\begin{array}{l}\text { Flip-flop design; } \\
\text { deviant-alone condition }\end{array}$ & No MMN & $\mathrm{N} / \mathrm{A}$ \\
\hline $\begin{array}{l}\text { Roger et al. } \\
\text { (2009) }\end{array}$ & Awake & $\begin{array}{l}\text { Active sensors - two on parietal } \\
\text { cortices (bregma AP }-4.0 \mathrm{~mm}, \mathrm{~L} \\
+2.5 \mathrm{~mm} \text { ). } \\
\text { Reference - bregma AP } 4.5 \mathrm{~mm}, \mathrm{~L} \\
1.6 \mathrm{~mm} .\end{array}$ & $\begin{array}{l}\text { Shorter } \\
\text { duration }\end{array}$ & No flip-flop & $-v e$ & $\begin{array}{l}25-75 \text { after } \\
\text { deviant off- } \\
\text { set }\end{array}$ \\
\hline $\begin{array}{l}\text { Ruusuvirta } \\
\text { et al. (1998) }\end{array}$ & $\begin{array}{l}\text { Urethane- } \\
\text { xylazine }\end{array}$ & $\begin{array}{l}\text { Active sensor positioned on the } \\
\text { basis of response to click stimuli } \\
\text { within a } 5 \text {-mm } \times 5 \text {-mm exposed } \\
\text { region with the rostral edge, } 3 \mathrm{~mm} \\
\text { posterior to bregma and the } \\
\text { medial edge } 5 \mathrm{~mm} \text { lateral to the } \\
\text { midline. Reference - a skull screw } \\
\text { on the right cerebellar cortex. }\end{array}$ & Frequency & $\begin{array}{l}\text { Flip-flop design; } \\
\text { deviant-alone condition }\end{array}$ & $+\mathrm{ve}$ & 63-196 \\
\hline $\begin{array}{l}\text { Ruusuvirta } \\
\text { et al. (2007) }\end{array}$ & Urethane & $\begin{array}{l}\text { Active sensor - bregma AP } \\
-5.0 \mathrm{~mm}, \mathrm{~L} 7.0 \mathrm{~mm} \text {. } \\
\text { Reference - lambda AP } 1.0 \mathrm{~mm}, \mathrm{R} \\
1.0 \mathrm{~mm} \text {. }\end{array}$ & $\begin{array}{l}\text { Melodic } \\
\text { contour }\end{array}$ & Flip-flop design & $\begin{array}{l}\text { Polarity varied } \\
\text { across animals }\end{array}$ & $106-136$ \\
\hline
\end{tabular}


Table 1 | Continued

\begin{tabular}{|c|c|c|c|c|c|c|}
\hline Author & $\begin{array}{l}\text { State: awake } \\
\text { vs. anesthesia }\end{array}$ & $\begin{array}{l}\text { Location of active and } \\
\text { reference sensors }\end{array}$ & $\begin{array}{l}\text { Deviant } \\
\text { feature }\end{array}$ & Design controls & $\begin{array}{l}\text { Polarity of MMN } \\
\text { response }\end{array}$ & $\begin{array}{l}\text { Window of } \\
\text { effect (ms) }\end{array}$ \\
\hline $\begin{array}{l}\text { Tikhonravov } \\
\text { et al. (2008) }\end{array}$ & $\begin{array}{l}\text { Pentobarbital } \\
\text { sodium }\end{array}$ & $\begin{array}{l}\text { Active sensor - bregma AP } \\
-4.5 \mathrm{~mm} \text {, R } 3.5 \mathrm{~mm} \text {. } \\
\text { Reference - lambda AP }-2.0 \mathrm{~mm} \text {, } \\
\mathrm{L} 2.0 \mathrm{~mm} \text {. }\end{array}$ & Frequency & $\begin{array}{l}\text { Flip-flop design; } \\
\text { deviant-alone condition }\end{array}$ & + ve & $150-180$ \\
\hline $\begin{array}{l}\text { Tikhonravov } \\
\text { et al. (2010) }\end{array}$ & $\begin{array}{l}\text { Pentobarbital } \\
\text { sodium }\end{array}$ & $\begin{array}{l}\text { Active sensor - bregma AP } \\
-4.5 \mathrm{~mm} \text {, R } 5.0 \mathrm{~mm} \text {. } \\
\text { Reference - lambda AP }-2.0 \mathrm{~mm} \text {, } \\
\mathrm{L} 2.0 \mathrm{~mm} \text {. }\end{array}$ & Frequency & $\begin{array}{l}\text { Flip-flop design; } \\
\text { deviant-alone condition }\end{array}$ & + ve & $91-180$ \\
\hline
\end{tabular}

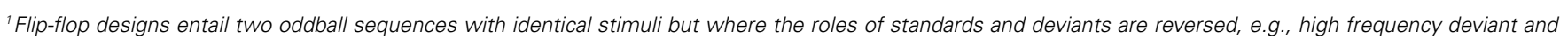

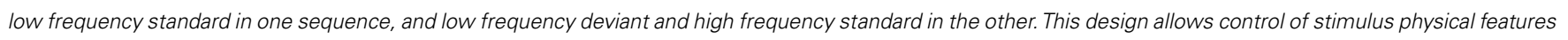
in deviant minus standard difference waves. $L$, left from the midline, $R$, right from the midline.

${ }^{2}$ Active electrodes were not positioned on the dura but in lower cortical layer (IV-VI), although the reference was on the dura.

( $5 \mathrm{mg} / \mathrm{kg}$ s.c.) and buprenorphine $(0.01 \mathrm{mg} / \mathrm{kg}$ s.c. $)$ were administered pre-operatively as analgesics. The animals were allowed to recover for at least 6 days after surgery before the first ERP recordings in the awake state.

Event-related potentials were recorded in a plastic experimental chamber with sides covered with grounded copper mesh using custom EEG software written in LabVIEW (version 8.2.1). The experimental chamber was located inside a Faraday cage. The rat was placed in a partition (internal dimensions: length $23.5 \mathrm{~cm}$, width $12.0 \mathrm{~cm}$, height $24.0 \mathrm{~cm}$ ) within the experimental chamber. For recordings in the anesthetized state, the animal was placed on its side on the bedding lengthwise in the partition. Three channels of data were continuously digitized $(1 \mathrm{kHz})$ : a single EEG-channel, square wave signals generated by the PC sound card in parallel with the auditory stimulus and stimulus event codes. The bandwidth of the data acquisition system was $0.2-150 \mathrm{~Hz}$ and the input voltage range was $\pm 10 \mathrm{mV}$.

\section{SOUND GENERATION}

Auditory stimuli were generated with a custom program written in Presentation (Version 14.1, Neurobehavioral Systems, Inc.), amplified, and delivered through a speaker $(50 \mathrm{~Hz}-19 \mathrm{kHz}$ frequency response) mounted at an approximate height of $1 \mathrm{~m}$ above the floor of the experimental chamber. Sound intensity was calibrated with a sound meter (Brüel \& Kjær Model 2260) and varied between 96 and $105 \mathrm{~dB}$ SPL across locations within the chamber for the sounds in the 2 - and $4.5-\mathrm{kHz}$ range utilized in this study. Thresholds for rats in this range are between 35 and $45 \mathrm{~dB}$ SPL (Jamison, 1951; Gourevitch, 1965; Mazurek et al., 2010).

\section{EXPERIMENTAL DESIGN, STIMULUS CHARACTERISTICS, AND STIMULUS PRESENTATION}

There were three types of stimulus sequences (see Figure 1A). There were two oddball sequences consisting of simple invariance deviants, where the roles of the deviant and standard were reversed (flip-flop conditions) resulting in either an ascending deviant sequence or a descending deviant sequence. The third condition was a many-standards control sequence in which stimuli equivalent to the deviants of the oddball sequences were presented at the same probability as in the oddball sequences but interspersed with other varying sounds that precluded establishment of regularity in background sounds (Jacobsen and Schröger, 2001; Nelken and Ulanovsky, 2007). Rats were tested on one frequency and one duration block within each test session in counterbalanced order across rats with a 5-min break between the two blocks. Each block contained 12 subblocks (3 experimental sequences repeated 4 times). Each subblock consisted of 250 tones in either an ascending deviant oddball sequence, a descending deviant oddball sequence or a control sequence.

In the ascending and descending oddball sequences (Figure 1A), $80 \%$ of the tones were standards (ST) and $20 \%$ deviants (DEV). Tones were presented in a pseudorandom order with the constraint that there was at least one ST before each DEV. In the control sequence, there were five types of tone bursts each presented with $20 \%$ probability to match the probability of the DEV in the ascending or descending oddball sequences. Tones were presented in pseudorandom order except that no tone was ever repeated. For all sequences, tones had a $10-\mathrm{ms}$ rise and fall time and a stimulus onset asynchrony (SOA) of $500 \mathrm{~ms}$.

For the frequency oddball blocks, two tone bursts of $100 \mathrm{~ms}$ duration were used: low frequency (LF) of $2500 \mathrm{~Hz}$ and high frequency (HF) of $3600 \mathrm{~Hz}$ equivalent to a normalized frequency difference (or $\Delta f$ ) of 0.37 , the largest frequency separation employed by Ulanovsky et al. (2003). In the ascending oddball sequence, the LF and HF tone bursts were the ST and DEV respectively. In the descending oddball sequence, the DEV and ST were reversed. In the many-standards control sequences, five frequencies (each of $100 \mathrm{~ms}$ duration) differing on a logarithmic scale were presented: $2083 \mathrm{~Hz}, 2500$ (LF) Hz, $3000 \mathrm{~Hz}, 3600$ (HF) Hz, and $4320 \mathrm{~Hz}$. These tones were presented with a probability of $20 \%$ in a pseudorandom order, except for the constraint noted above.

For the duration oddball blocks, two durations, short duration (SD) of $50 \mathrm{~ms}$ and a long duration (LD) of $150 \mathrm{~ms}$, were used (both $3000 \mathrm{~Hz}$ ) based on the observation by Roger et al. (2009) that these durations resulted in robust MMN-like activity in the rat in a descending sequence. In the ascending oddball sequence, the SD and LD tones were the ST and DEV respectively. In the descending sequence, the ST and DEV were reversed. The duration control 


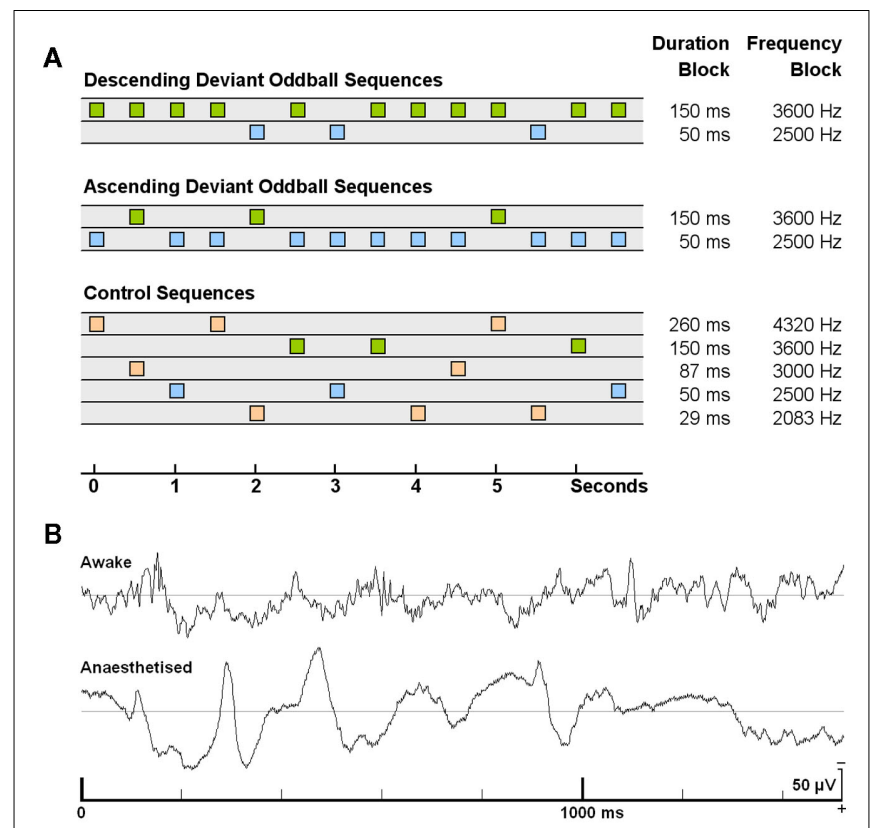

C

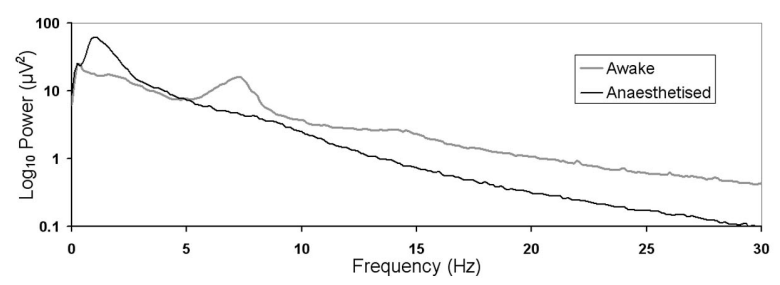

FIGURE 1 | (A) Schematic of the experimental design. There were three types of sequences: (i) descending oddball deviants $(20 \%)$ in blue amongst high frequency/long duration standards in green, (ii) ascending oddball deviants $(20 \%)$ in green among low frequency/short duration standards in blue, and (iii) control deviants (20\%) with many standards (each $20 \%$ probability) in orange and stimuli equivalent to the deviant stimuli of the oddball sequences in blue and green. The SOA is $500 \mathrm{~ms}$. Columns on the right depict the frequencies and durations used in frequency and duration sequences respectively (modified from Maess et al., 2007). (B) $1.5 \mathrm{~s}$ sample of epidural EEG in one animal in awake and anesthetized state. (C) EEG power spectra in the awake and anesthetized state. Computed using FFT of 10 s Hanning windowed EEG epochs, averaged across all sessions from seven rats.

sequence consisted of five tones at $3000 \mathrm{~Hz}$ differing in durations on a logarithmic scale, $29 \mathrm{~ms}, 50$ (SD) ms, $87 \mathrm{~ms}, 150$ (LD) ms, and $260 \mathrm{~ms}$.

In order to avoid the possibility of an MMN being elicited by tones at the extremes of a range for either the frequency or duration control conditions, known as the extreme sub-standard effect (Winkler et al., 1990; Jacobsen and Schröger, 2001; Jacobsen et al., 2003) that is particularly marked for duration (Jacobsen and Schröger, 2003), the ST and DEV frequencies and durations used in the descending and ascending sequences were the second and the fourth highest frequencies or durations in the frequency and duration control sequences respectively (Figure 1A).

Each animal underwent four recording sessions in an awake state on different days. The rat was placed in the partition of the experimental chamber with bedding for $15 \mathrm{~min}$ before each session to acclimatize. Each session lasted approximately $65 \mathrm{~min}$. The rat did not have access to food or water during the session but was free to explore during the recordings. For recordings in the anesthetized state, the animal was placed in the partition (15 min) after it was anesthetized with fentanyl $(300 \mu \mathrm{g} / \mathrm{kg}$ i.p. $)$ and medetomidine $(300 \mu \mathrm{g} / \mathrm{kg}$ i.p.). Two recording sessions under anesthesia occurred on the same day. This study was part of a larger project that also investigated the effects of SOA on early ERP components in sessions that were of approximately $60 \mathrm{~min}$ duration. For five animals, the four MMN sessions in the awake state preceded the two MMN sessions under anesthesia; in one animal, the anesthesia sessions occurred after three awake sessions; and in the other, anesthesia sessions occurred after two awake sessions.

\section{DATA ANALYSIS}

The anesthesia data in general were noisier than the awake data, partly because the EEG during anesthesia exhibited high amplitude slow wave activity that contributed to unstable prestimulus baselines and slow fluctuations in the post-stimulus epochs (Figure 1B) and partly because of the fewer sessions recorded under anesthesia compared to awake sessions (two vs. four sessions). The frequency spectrum of the awake EEG was maximal at low frequencies, and decreased monotonically with frequency, except for a large peak between 6 and $8 \mathrm{~Hz}$ (Figure 1C). In contrast, the EEG under anesthesia had a peak at $1 \mathrm{~Hz}$ which was four times the amplitude of the spectrum in the awake data, and no peak in the 6- to $8-\mathrm{Hz}$ band consistent with previous reports of increased activity in the delta frequency band $(0.5-4.0 \mathrm{~Hz})$ in the rat with fentanyl administration (Cox et al., 1999; Haberham et al., 2000).

Data processing was performed off-line with EEG Display 6.1.5 (Fulham, 2009). For the analyses of the auditory ERPs, epochs were extracted from the continuous EEG consisting of a 50-ms prestimulus baseline and a 200-ms post-stimulus interval. An artifact rejection threshold was set independently for each rat/recording session at 5 standard deviations of the raw EEG signal amplitude relative to the pre-stimulus baseline. On average, this resulted in $3 \%$ of the trials being rejected (range 1-13\%). The single female rat exhibited very large amplitude evoked responses. As all statistical comparisons were within subject comparisons, this animal's data were scaled down by multiplying by 0.25 .

The first 25 tones at the start of each tone sequence were excluded from analysis to allow for transitory effects associated with switching between different types of sequences. Although the stimulus generation paradigm incorporated a rule that every DEV must be preceded by at least one ST, preliminary analysis showed that there was virtually no MMN-like response for oddball DEVs that were preceded by only one ST. Therefore, only EEG epochs to oddball DEVs and STs preceded by at least two STs were used in the main analysis focused on determining whether an MMN is present or not. Similarly, only epochs to control DEVs preceded by at least two tones of a different type were included.

Following these pre-processing steps, epochs were averaged offline for each animal and session separately and ERPs extracted for each of the four basic stimulus types (HF and LF in the frequency blocks, and LD and SD in the duration blocks). For the 
main analysis, we extracted ERPs to each stimulus type when they were:

i. Oddball DEVs, that is, when the stimulus was the deviant in an oddball sequence,

ii. All STs, that is, when the stimulus was the standard in an oddball sequence averaged over all standards in the sequence,

iii. STs before deviants, that is, when the stimulus was the standard in an oddball sequence but averaged over only standards that occurred immediately before the deviant (this ensures equivalent S/N for STs and DEVs, Ruusuvirta et al., 1998) or

iv. Control DEVs, that is, when the stimulus occurred in a control sequence.

In general, there was little difference between ERPs to all STs and ERPs to STs before deviants in oddball runs, so the results of the latter analysis are not reported here for the main MMN analysis. Two difference waveforms were also extracted in which ERPs to all STs and control DEVs were subtracted from oddball DEVs. As outlined in the results, other post-processing of oddball DEVs and STs was undertaken in addition to the main MMN analysis to explore the effects of stimulus sequence structure, for example, the number of STs preceding a deviant in oddball sequences.

Mean amplitudes were extracted over windows that captured peaks and troughs in the ERPs to the stimulus onsets of tone bursts and effects evident in contrasts of (i) oddball DEV ERPs with ST ERPs and (ii) oddball DEV ERPs with control DEV ERPs. As the latencies of ERP components differed in awake and in anesthetized data and as effects in DEV ERP contrasts differed across frequency and duration oddball sequences, windows that capture these features are described in the Section "Results." Mean amplitudes measuring these components and effects were analyzed in general as repeated measures analyses of variance (ANOVAs), with factors appropriate for the question of interest using a significance level of 0.05 , although some outcomes approaching 0.05 are reported as trends. In instances where multiple levels were compared (such as the effect on ERP amplitudes of the five stimulus frequencies/durations from the control sequences) and where sphericity was violated, Huynh-Feldt adjusted degrees of freedom were used to determine significance levels.

\section{RESULTS \\ EPIDURAL ERP MORPHOLOGY IN THE AWAKE AND ANESTHETIZED RATS}

Event-related potentials to the onsets of brief tone bursts recorded from an active epidural electrode located over right auditory cortex (and a more posteriorly located left hemisphere reference) in unrestrained rats exhibited distinct components over the first $200 \mathrm{~ms}$ (Figure 2A), although the amplitudes of these components differed according to stimulus attribute (HF, LF, LD, and SD stimuli). In general, they were characterized by a negative component peaking at approximately $29 \mathrm{~ms}$ (denoted as N29 AW), followed by

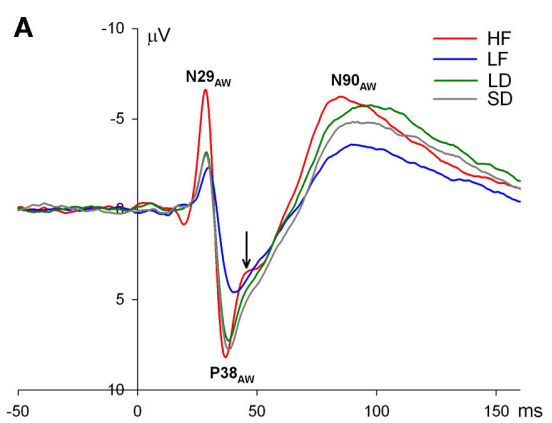

C

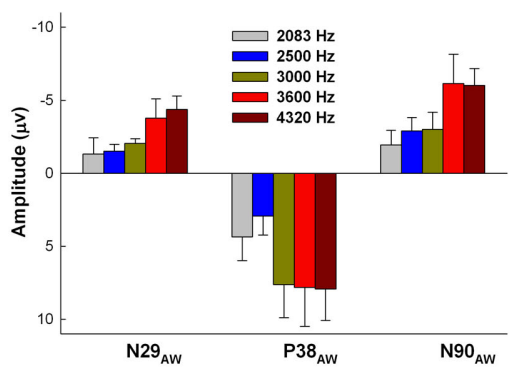

FIGURE 2 | Epidural recorded ERPs in the awake rat during oddball and many-standards control sequences. (A) ERPs to each of the four stimuli of high frequency (HF), low frequency (LF), long duration (LD), and short duration (SD), averaged over oddball sequences showing three exogenous peaks $\mathrm{N}_{2} 9_{\mathrm{AW}}, \mathrm{P} 38_{\mathrm{AW}}$, and $\mathrm{N}_{\mathrm{AW}}$. The arrow indicates the notch in the HF ERP between $\mathrm{P} 38_{\mathrm{AW}}$ and $\mathrm{N}_{\mathrm{AW}}$. (B) ERPs to the range of frequencies used in the many-standards frequency control
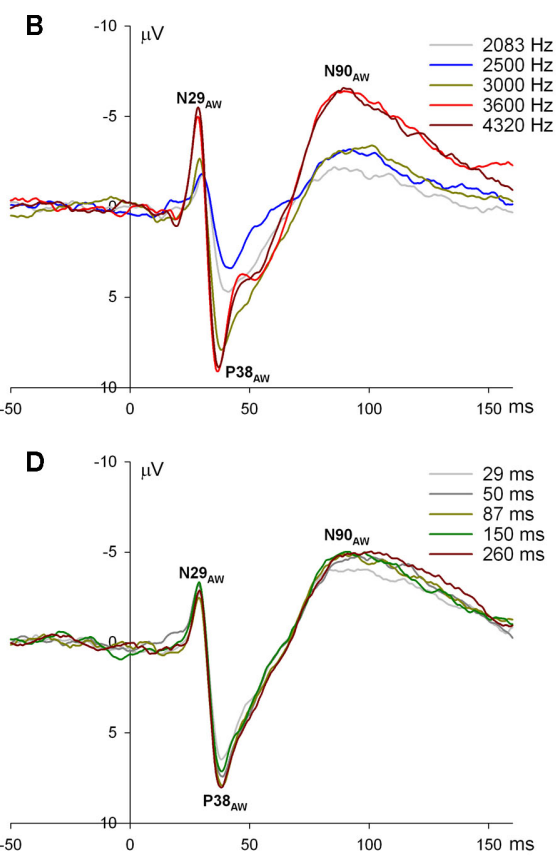

sequence showing that all three exogenous peaks increase with increasing frequency. (C) The mean amplitude (with SE) of N29 $9_{\text {AW, }}$ P38 $8_{\text {AW }}$ and $\mathrm{N} 0_{\mathrm{AW}}$ as function of increasing frequency. (D) ERPs to the range of durations used in many-standards duration control sequence showing little effect of increasing duration on the three exogenous peaks. Note that there is no evidence of an offset response in the awake state in $\mathbf{( A , B , D ) . ~}$ 
a positive peak at $38 \mathrm{~ms}\left(\mathrm{P} 38_{\mathrm{AW}}\right)$ and a second broad negative component with a peak latency of approximately $90 \mathrm{~ms}\left(\mathrm{~N} 90_{\mathrm{AW}}\right)$.

Three mean amplitude measures were extracted over latency windows corresponding to these peaks in awake ERPs: a 4-ms window from 27 to $31 \mathrm{~ms}$ centered on $\mathrm{N} 29_{\mathrm{AW}}$, a 4 -ms window from 37 to $41 \mathrm{~ms}$ around $\mathrm{P} 38_{\mathrm{AW}}$, and a $20-\mathrm{ms}$ window from 80 to $100 \mathrm{~ms}$ around $\mathrm{N} 90_{\mathrm{AW}}$. The HF stimulus also generated an early $\mathrm{P} 19_{\mathrm{AW}}$ preceding $\mathrm{N} 29_{\mathrm{AW}}$ that was not evident in ERPs to the other stimuli and a discernible notch between $\mathrm{P} 38_{\mathrm{AW}}$ and $\mathrm{N} 90_{\mathrm{AW}}$ at approximately $42 \mathrm{~ms}$. The HF stimulus generated the largest $\mathrm{N} 29_{\mathrm{AW}}$ and N90 AW peaks while the LF stimulus generated the smallest P38 and $\mathrm{N} 90_{\mathrm{AW}}$ peaks. The effect of tone burst frequency on the amplitudes of $\mathrm{N} 29_{\mathrm{AW}}, \mathrm{P} 38_{\mathrm{AW}}$, and $\mathrm{N} 90_{\mathrm{AW}}$ components is most clearly evident in the ERPs to the frequencies utilized in the manystandards frequency control sequence (Figure 2B). Repeated measures ANOVAs with tone burst frequency as a single repeated measures factor on $\mathrm{N} 29_{\mathrm{AW}}, \mathrm{P} 38_{\mathrm{AW}}$, and N90 $\mathrm{AW}$ mean amplitude measures confirmed the frequency differences and revealed a linear increase in amplitude of each component with increasing frequency, although for $\mathrm{P} 38_{\mathrm{AW}}$ and $\mathrm{N} 90_{\mathrm{AW}}$, there was evidence of a significant fourth order non-linear contribution of increasing frequency as well $\left[\mathrm{N} 29_{\mathrm{AW}}: F(1.84,11.05)=4.42, p=0.041\right.$, linear contrast $-F(1,6)=33.16, p=0.001 ; \mathrm{P} 38_{\mathrm{AW}}: F(4,24)=4.31$, $p=0.009$, linear contrast $-F(1,6)=9.51, p=0.022$, quartic contrast $-F(1,6)=8.58, p=0.026 ; \mathrm{N} 90_{\mathrm{AW}}: F(2,24)=9.04$, $p<0.001$, linear contrast $-F(1,6)=22.52, p=0.003$, quartic contrast $-F(1,6)=10.33, p=0.018$; Figure 2C]. Differing durations from the many-standards duration control sequence had little effect on the same components (Figure 2D). Despite the LD of some tone bursts, there was no evidence of offset responses in the expected latency range after stimulus offset (see Figure 2D for 29, 50 , and $87 \mathrm{~ms}$ durations).

Event-related potentials to the onset of brief tone bursts in the anesthetized rat exhibited components that differed markedly in morphology, amplitude, and latency to the awake data (Figures 3A-C). They were characterized by small amplitude components in general consisting of an early negative peak at $17 \mathrm{~ms}$, $\mathrm{N} 17_{\mathrm{AN}}$ (a negative peak at $17 \mathrm{~ms}$ in the anesthesia data), a subsequent positive peak at $44 \mathrm{~ms}, \mathrm{P} 44_{\mathrm{AN}}$, and a second negative peak at $67 \mathrm{~ms}, \mathrm{~N} 67_{\mathrm{AN}}$, and a second positive peak at $90 \mathrm{~ms}, \mathrm{P} 90_{\mathrm{AN}}$.

Three mean amplitude measures were extracted over latency windows corresponding to first three peaks in onset potentials: a 4 -ms window from 15 to 19 ms centered on $\mathrm{N} 17_{\mathrm{AN}}$, a 4 -ms window from 42 to $46 \mathrm{~ms}$ around $\mathrm{P} 44_{\mathrm{AN}}$, and a 4 -ms window from 65 to $69 \mathrm{~ms}$ around N67 $\mathrm{AN}$. There was no significant systematic relationship between the amplitude of onset potentials, $\mathrm{N} 17_{\mathrm{AN}}, \mathrm{P} 44_{\mathrm{AN}}$, and $\mathrm{N} 67_{\mathrm{AN}}$, and tone burst frequencies from the many-standards frequency control condition $\left[\mathrm{N}_{17} 7_{\mathrm{AN}}\right.$ : $F(4,24)=2.23, p=0.096 ; \mathrm{P}_{4} 4_{\mathrm{AN}}: F(4,24)=1.60, p=0.207$; $\mathrm{N}^{6} 7_{\mathrm{AN}}: F(4,24)=1.25, p=0.317$; Figure $\left.3 \mathrm{~B}\right]$. There was no effect of stimulus duration on onset potentials [N17 ${ }_{\mathrm{AN}}: F(4$, $24)=1.30, p=0.297$; P44 $4_{\mathrm{AN}}: F(4,24)=1.18, p=0.345$ N67 $_{\mathrm{AN}}$ : $F(4,24)=1.46, p=0.247$; Figure $3 \mathrm{C}$ ] but in contrast to awake data, there was evidence of offset potentials consisting of negative and positive peaks approximately 28 and $36 \mathrm{~ms}$ following stimulus offset of the 50-, 87-, 150-, and 260-ms tone bursts (see Figure 3C for 50,87 , and $150 \mathrm{~ms}$ durations).
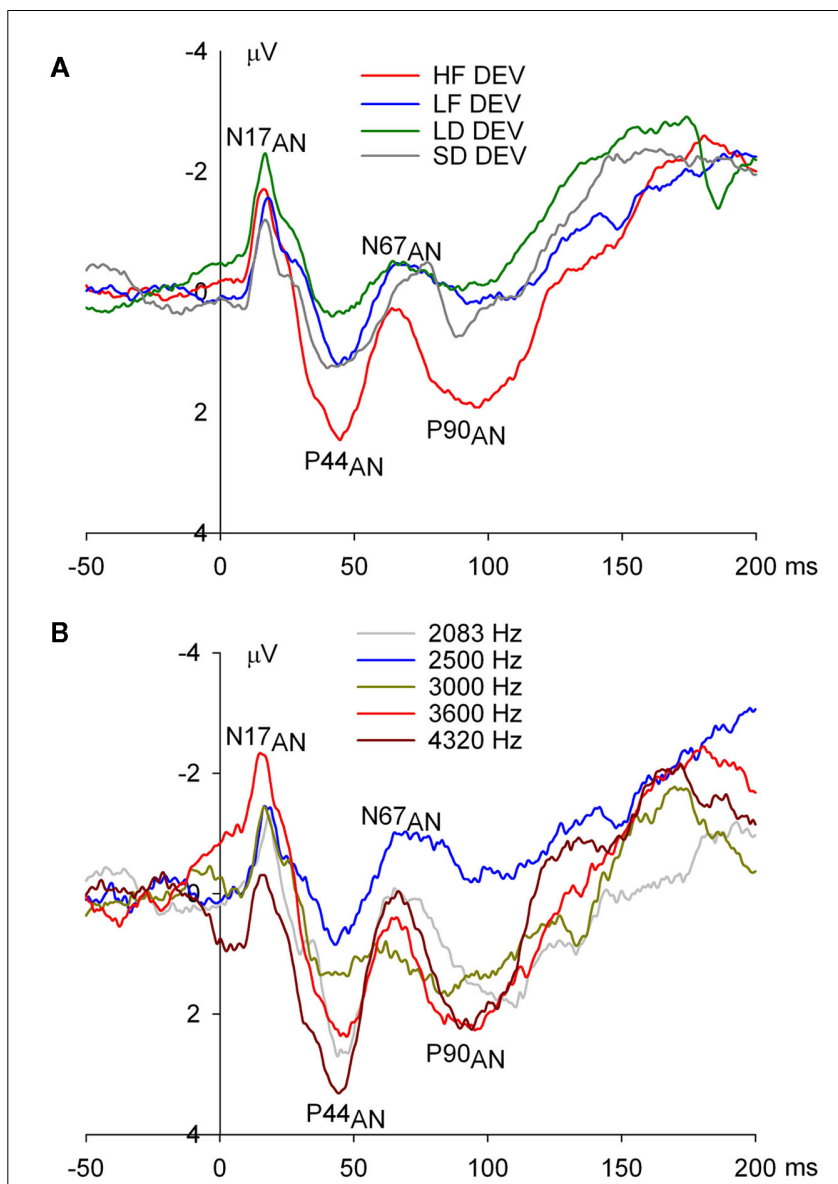

C

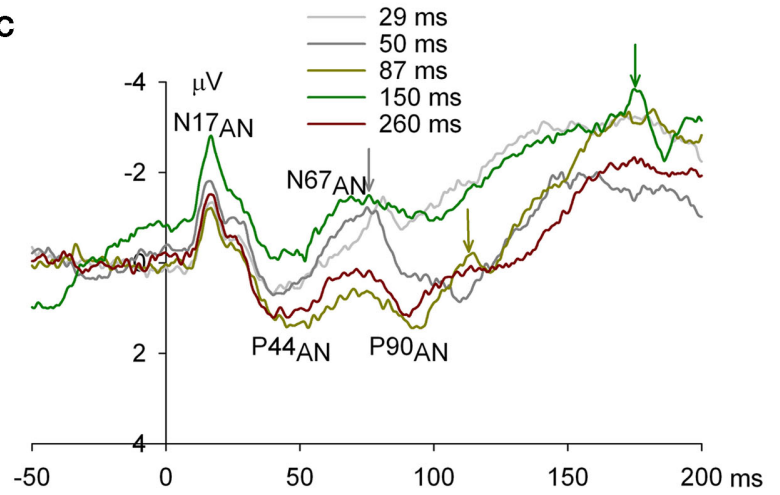

FIGURE 3 | Epidural recorded ERPs in the anesthetized rat during oddball and many-standards control sequences. (A) ERPs to each of the four key stimuli of high frequency (HF), low frequency (LF), long duration $(\mathrm{LD})$, and short duration (SD), averaged over oddball sequences showing four exogenous peaks $\mathrm{N} 17_{\mathrm{AN}}, \mathrm{P} 44_{\mathrm{AN}}, \mathrm{N} 67_{\mathrm{AN}}$, and $\mathrm{P} 9 \mathrm{O}_{\mathrm{AN}}$. The morphology of anesthetized rat ERPs was different to those of the awake rat, component amplitudes overall under anesthesia were reduced (note the different gains for Figure $\mathbf{2}$ and in this figure), and the peak latency of the earliest negative peak occurred earlier (17 vs. $29 \mathrm{~ms}$ ). (B) ERPs to the range of frequencies used in the many-standards frequency control sequence showing little systematic difference as a function of frequency. (C) ERPs to the range of durations used in the many-standards duration control sequence showing evidence of offset potentials consisting of negative and positive peaks approximately 28 (marked with arrows) and $36 \mathrm{~ms}$ after the offset of 50,87 , and 150 ms duration stimuli. 
EPIDURAL ERPS TO HIGH FREQUENCY AND LOW FREOUENCY ODDBALL DEVIANTS IN AWAKE RATS

High frequency oddball DEVs when compared to HF STs (Figure 4A) produced a larger $\mathrm{N} 29_{\mathrm{AW}}$ as well as a later negative shift after $\mathrm{P} 38_{\mathrm{AW}}$ with maximum separation at approximately $42 \mathrm{~ms}$ that persisted until approximately $90 \mathrm{~ms}$. The contrast between the HF oddball and HF control DEV ERPs produced a similar pattern except that the later negative separation was more marked over longer latencies. Two difference waves were derived: HF oddball DEV ERP minus HF ST ERP, and HF oddball DEV ERP minus control DEV ERP (Figure 4B). The first negative peak in the difference waves corresponds to $\mathrm{N} 29_{\mathrm{AW}}$. The second negative
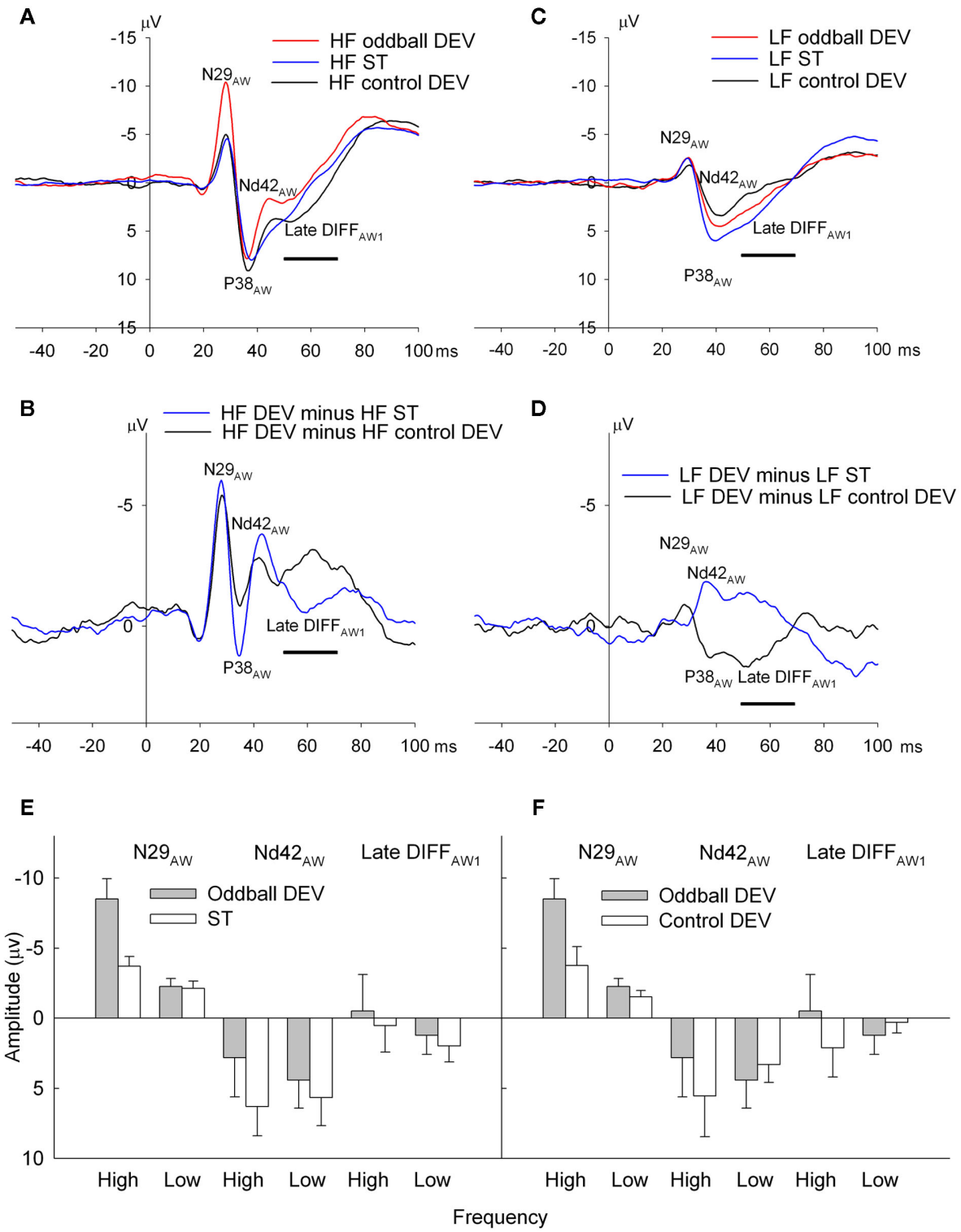

FIGURE 4 | Epidural recorded ERPs in the awake rat to oddball deviant (oddball DEV), standard (ST) and control deviant (control DEV) in the frequency conditions. (A) ERPs to high frequency (HF) stimuli. $\mathrm{N} 29_{\mathrm{AW}}, \mathrm{Nd} 42_{\mathrm{AW}}$, and late DIFF $\mathrm{AW}_{1}$ are all more negative in the oddball DEV ERP (red) than in the ST (blue) and control DEV (black). The black horizontal bar depicts the latency window over which late DIFF AW1 $_{1}$ was measured. (B) MMN difference waves for HF stimuli: HF oddball DEV minus HF ST (blue), which can reflect both deviance detection and adaptation effects vs. difference waves derived using control deviants, HF oddball minus HF control DEV (black), which reflects deviance detection. (C) ERPs to low frequency (LF) stimuli. N29 $9_{\mathrm{AW}}, \mathrm{Nd} 42_{\mathrm{AW}}$, and late DIFF show inconsistent differences between the oddball DEV ERP (red) relative to the LF ST (blue) and relative to the control DEV (black). (D) MMN difference waves for LF stimuli: LF oddball DEV minus LF ST (blue), difference waves derived using control deviants, LF oddball minus LF control DEV (black). Only the oddball DEV minus ST difference wave shows similarities in terms of polarity to the HF pattern (except for the effect on N29 $9_{A W}$ ). (E) The mean amplitude (with SE) of $N 29_{A W}, N d 42_{A W}$, and late DIFF ${ }_{A W 1}$ measures generated by high and low frequency oddball DEVs (gray) and STs (white). (F) The mean amplitude (with SE) of $\mathrm{N} 29_{A W}, \mathrm{Nd} 42_{\mathrm{AW}}$ and late DIFF AW1 $_{1}$ measures generated by high and low frequency oddball DEVs (gray) and control DEVs (white). 
peak in the difference waveforms will be called $\mathrm{Nd} 42_{\mathrm{AW}}$ (a negative deflection at $42 \mathrm{~ms}$ in the MMN difference waveforms in the awake animal). This corresponds to the notch in the negative going arm of $\mathrm{N} 0_{\mathrm{AW}}$ in the raw waveforms (Figure 4A). The later negativity in the difference waveforms will be called the late DIFF $\mathrm{AW}_{\mathrm{AW}}$ (the first late difference measure in the awake animal to distinguish it from other later effects in the duration deviant oddball paradigms).

As noted earlier, LF tone bursts in general elicited smaller amplitude ERPs than HF stimuli (Figures 2A,B) emphasizing the importance in animal models of controlling for stimulus features in MMN paradigms when recording epidural potentials as well as MUAs and eLFPs (Nelken and Ulanovsky, 2007). While inspection of the LF ERPs averaged across all seven animals (Figure 4C) suggest differences between LF oddball DEV compared with LF ST and LF control DEV ERPs, particularly in the interval following $\mathrm{P} 38_{\mathrm{AW}}$, the two difference waveforms created from LF oddball DEV vs. LF ST and LF control DEV respectively were of opposite polarity from 30 to $70 \mathrm{~ms}$ (Figure 4D) and bore no resemblance to the HF data.

In order to capture the oddball DEV effects for both HF and LF stimuli, in addition to $\mathrm{N} 29_{\mathrm{AW}}$, two additional mean amplitudes were extracted from oddball DEV, all standards, and control DEV ERPs: Nd42 AW was measured over a 4-ms window from 40 to $44 \mathrm{~ms}$ centered near the second negative peak in difference waves, and late $\mathrm{DIFF}_{\mathrm{AW} 1}$ over a 20 -ms window from 50 to $70 \mathrm{~ms}$ over longer latencies of the difference wave. These two measures together with $\mathrm{N} 29_{\text {AW }}$ were intended to capture the early and later differences evident in the HF and LF difference waveforms.

Omnibus two-way repeated measures ANOVAs were carried out on each of the ERP measures, $\mathrm{N} 29_{\mathrm{AW}}, \mathrm{Nd} 42_{\mathrm{AW}}$, and late $\mathrm{DIFF}_{\mathrm{AW} 1}$, with repeated measures on frequency (HF vs. LF stimuli) and stimulus type (either oddball DEV vs. ST or oddball DEV vs. control DEV). Where the interaction between stimulus frequency and type was significant, simple effect contrasts of oddball DEV vs. ST or control DEV were conducted.

For the ANOVA in which stimulus type factor contrasted oddball DEV with ST ERPs, the oddball DEV produced a negative displacement of both $\mathrm{N} 29_{\mathrm{AW}}$ and $\mathrm{Nd} 42_{\mathrm{AW}}$ relative to the ST $\left[\mathrm{N} 29_{\mathrm{AW}}: F(1,6)=7.99, p=0.03 ; \mathrm{Nd} 42_{\mathrm{AW}}: F(1,6)=43.46\right.$, $p=0.001]$. There was no evidence of a similar effect on late $\mathrm{DIFF}_{\mathrm{AW} 1}$. N29 $\mathrm{AW}$ was also larger (more negative) to HF than LF stimuli $[F(1,6)=13.10, p=0.011]$ but exhibited a significant stimulus frequency by type interaction $[F(1,6)=8.93, p=0.024]$, indicating that the magnitude of the oddball DEV vs. ST difference varied with stimulus frequency. Simple contrasts indicated that there was a significant difference in N29 ${ }_{\text {AW }}$ between oddball DEV and ST for HF stimuli only ( $t=4.6, p=0.004$; Figure $4 \mathrm{E})$. In contrast, both HF and LF oddball DEVs exhibited more negative $\mathrm{Nd} 42_{\mathrm{AW}}$ than STs. However, as noted earlier, differences between oddball DEV and ST could be because the deviant response is less adapted due to its rare occurrence. The crucial question is whether epidural ERPs reflect deviance detection in a context of background regularity.

To address this question we contrasted the oddball DEV with the control DEV (see Figures 4A,C,F). N29 AW was larger for the oddball DEV $[F(1,6)=7.99, p=0.030]$ and larger for HF stimuli
$[F(1,6)=13.20, p=0.011$; Figure 4F $]$. Similar main effects were not evident for $\mathrm{Nd} 42_{\mathrm{AW}}$. The interaction between stimulus frequency and type was significant for all three components [N29 AW: $F(1,6)=8.93, p=0.024 ; \mathrm{Nd} 42_{\mathrm{AW}}: F(1,6)=6.65, p=0.042$; late $\left.\mathrm{DIFF}_{\mathrm{AW} 1}: F(1,6)=13.66, p=0.010\right]$. Simple contrasts indicated that the negative displacement of the oddball DEV relative to the control DEV was significant for HF stimuli only: N29 AW $(t=2.94$, $p=0.026), \mathrm{Nd} 42_{\mathrm{AW}}(t=2.70, p=0.036)$, late $\mathrm{DIFF}_{\mathrm{AW} 1}(t=2.55$, $p=0.043$; Figure 4F).

The outcomes from the two contrasts are quite similar - with the exception that in the oddball deviant vs. control deviant contrast only HF stimuli exhibit a larger (more negative) $\mathrm{Nd} 42_{\mathrm{AW}}$ and there are more robust effects on late $\mathrm{DIFF}_{\mathrm{AW} 1}$ (compare Figures 4A-F). Therefore, it appears that ERPs to the HF oddball deviant, at least in the awake animal, reflect deviance detection relative to background context, and not solely rarity. These deviance detection effects as defined here are evident in the earliest ERP component (i.e., N29) that occurred in epidural recordings in response to frequencies across the control frequency range and therefore might be considered an effect on an exogenous component. The deviance detection effects over later latencies, the first peaking at approximately $42 \mathrm{~ms}$ (referred to here as $\mathrm{Nd} 42_{\mathrm{AW}}$ ) and the second, a slow negative displacement spanning a broad interval (late $\mathrm{DIFF}_{\mathrm{AW} 1}$ ) do not appear to be effects on exogenous components. There is no clear evidence of $\mathrm{Nd} 42_{\mathrm{AW}}$ as a separate exogenous ERP component across the frequency range although it appears to coincide with a notch between $\mathrm{P} 38_{\mathrm{AW}}$ and N90 AW in ERPs to the two highest frequencies $(3600$ and $4320 \mathrm{~Hz}$; Figure 2B). The slow negative displacement over longer latencies does not coincide with any exogenous peak. These data suggest that we have recorded MMN-like activity to HF tone bursts in the awake rat.

To support this conclusion, we also examined the temporal evolution of responses to standards and deviants to determine whether these MMN-like effects to HF tone bursts are sensitive to the short-term stimulus history of background regularity. For this analysis we determined whether the number of preceding standards had a systematic effect on oddball DEV ERPs (Figure 5A left panel) using ANOVAs with a single repeated measures factor with five levels $(1,2,3,4$, or $5+$ STs preceding the DEV). It was found that $\mathrm{N} 29_{\mathrm{AW}}$ increased in amplitude as a function of the number of preceding standards $[F(4,24)=3.74, p=0.017$, linear contrast $-F(1,6)=12.33, p=0.013$, cubic contrast $-F(1$, $6)=7.69, p=0.032] . \mathrm{Nd} 42_{\mathrm{AW}}$ showed a similar pattern except that the cubic contrast was not significant $[F(4,24)=3.49, p=0.022$, linear contrast $-F(1,6)=8.54, p=0.027$ ] but there was no systematic effects of short-term stimulus history on the later negativ-

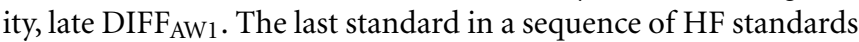
on the other hand, showed no systematic changes as a function of the number of preceding standards (Figure 5A - right panel; $F$-value $>0.05$ ). Difference waveforms were created to demonstrate the increasing negative displacements of oddball deviants more clearly by subtracting the ERPs to the common standard from deviant ERPs for deviants with 1-5+ preceding standards (Figure 5B) and means plotted for each component (Figure 5C). These demonstrate that $\mathrm{N} 29_{\mathrm{AW}}$ and $\mathrm{Nd} 42_{\mathrm{AW}}$ show different sensitivities to local stimulus history context (Figures 5B,C): N29 

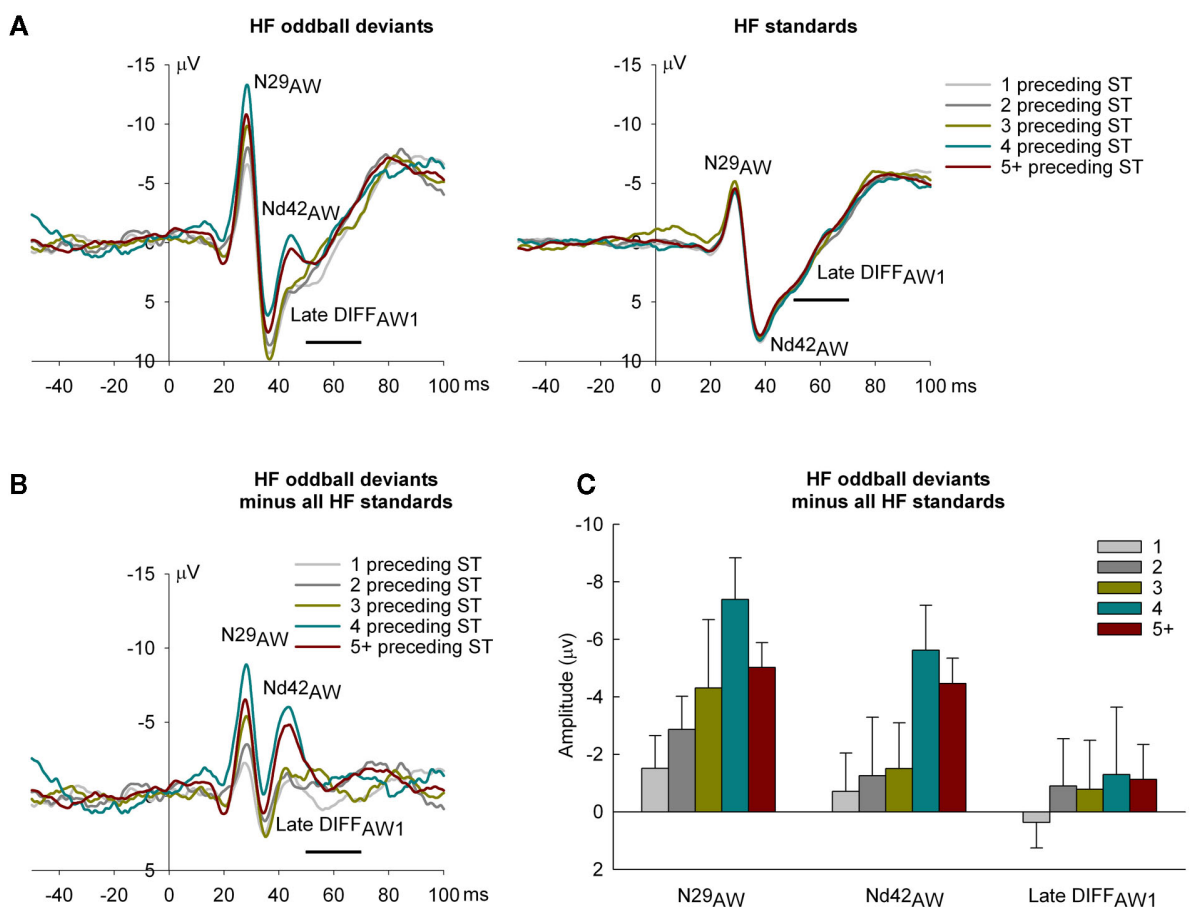

FIGURE 5 | Epidural recorded ERPs in the awake rat to high frequency (HF) deviants and standards and local recent stimulus history. (A) ERPS as a function of 1 (light gray), 2 (gray), 3 (dark yellow), 4 (dark cyan), and 5+ (dark red) preceding standards. Oddball deviants are on the left, standards on the right. $\mathrm{N}^{2} \mathrm{~S}_{\mathrm{AW}}$ and $\mathrm{Nd} 42_{\mathrm{AW}}$ in oddball deviant ERPs increase in general with the number of preceding standards but standard ERPs show no effect of preceding stimulus history. (B) Difference waves obtained by subtracting the common standard (HF standards) from the oddball deviant (HF oddball deviants) to demonstrate the effect of the number of preceding standards on $\mathrm{N} 29_{\mathrm{AW}}, \mathrm{Nd} 42_{\mathrm{AW}}$, and late DIFF $\mathrm{AW}_{1}$. (C) The mean amplitude (with SE) of N29 $9_{\mathrm{AW}}$, $\mathrm{Nd} 42_{\mathrm{AW}}$, and late DIFF $\mathrm{AW}_{1}$ measures of the difference wave (HF oddball deviants minus HF standards) demonstrating the effect of the number of preceding standards. N29 $9_{\text {AW }}$ amplitude shows a largely monotonic increase in amplitude with increasing standards. $\mathrm{Nd} 42_{\mathrm{AW}}$ amplitude is relatively unchanged with low numbers of preceding standards (1-3) but shows a marked increase when preceded by 4 or more standards. shows a monotonic increase in amplitude with 1-4 preceding standards and a decrease at $5+$ whereas $\mathrm{Nd} 42_{\mathrm{AW}}$ amplitude is constant over 1-3 preceding standards, but increases markedly at 4 and above. These results suggest that $\mathrm{Nd} 42_{\mathrm{AW}}$ may require a longer train of invariant sounds to establish regularity and encode deviance than $\mathrm{N} 29 \mathrm{AW}$.

There was no evidence of a systematic effect of the number of preceding standards on any components of LF oddball tone bursts (Figure not shown).

\section{EPIDURAL ERPS TO LONG DURATION AND SHORT DURATION ODDBALL DEVIANTS IN AWAKE RATS}

Unlike HF (or LF) DEVs, stimulus deviance for both LD and SD oddball DEVs can only be detected after $50 \mathrm{~ms}$ of a tone burst has elapsed. Therefore, one would not expect differences between oddball DEVs and STs or control DEVs prior to this point in time. As expected, LD oddball DEVs did not produce a larger N29 $\mathrm{AW}$ than LD STs. However unexpectedly, P38 $8_{\mathrm{AW}}$ appears larger, that is, more positive in LD oddball DEVs, particularly relative to $\mathrm{LD}$ STs (Figure 6A). At longer latencies, LD oddball DEVs showed a prolonged negative shift starting at $70 \mathrm{~ms}$ relative to LD ST ERPs. Similar late differences can be seen in the contrast between LD oddball DEVs and LD control DEVs (Figures 6A,B). SD oddball DEVs also exhibited differences relative to SD STs and consistent with the fact that information about duration deviance is only available after $50 \mathrm{~ms}$ has elapsed, these differences appear to onset at about $80 \mathrm{~ms}$. However, in contrast to LD oddball DEVs, SD oddball DEVs were more positive than SD STs and SD control DEVs over longer latencies (Figures 6C,D). To capture these late effects, a 60 -ms interval spanning longer latency displacements was extracted over a 100 - to $160-\mathrm{ms}$ and called here late $\mathrm{DIFF}_{\mathrm{AW} 2}$ to distinguish it from the late mean amplitude extracted for frequency oddball data. This measure was analyzed as well as N29 AW and $\mathrm{P} 38_{\mathrm{AW}}$ using repeated measures ANOVAs with two repeated measures factors, stimulus duration (long vs. short) and stimulus type (oddball DEV vs. ST or oddball DEV vs. control DEV).

There were no significant effects on N29 AW amplitude for either oddball DEV vs. ST or control DEV contrasts (all $p>0.3$ ). However P38 $8_{\mathrm{AW}}$ exhibited a significant interaction between stimulus duration and type for the oddball DEV vs. ST contrast $[F(1,6)=7.25, p=0.036]$ but not for the control DEV contrast $(p>0.3)$. Simple effects contrast revealed that $\mathrm{P} 38_{\mathrm{AW}}$ to the $\mathrm{LD}$ oddball DEV was significantly larger than the LD ST $(t=3.98$, $p=0.007$; Figure 6E). We will return to this unexpected effect later. The equivalent contrast for SD stimuli was not significant.

Over the later latency window selected to capture the late negative displacement of oddball DEVs, late DIFF sis breaking down this long interval to two smaller intervals 

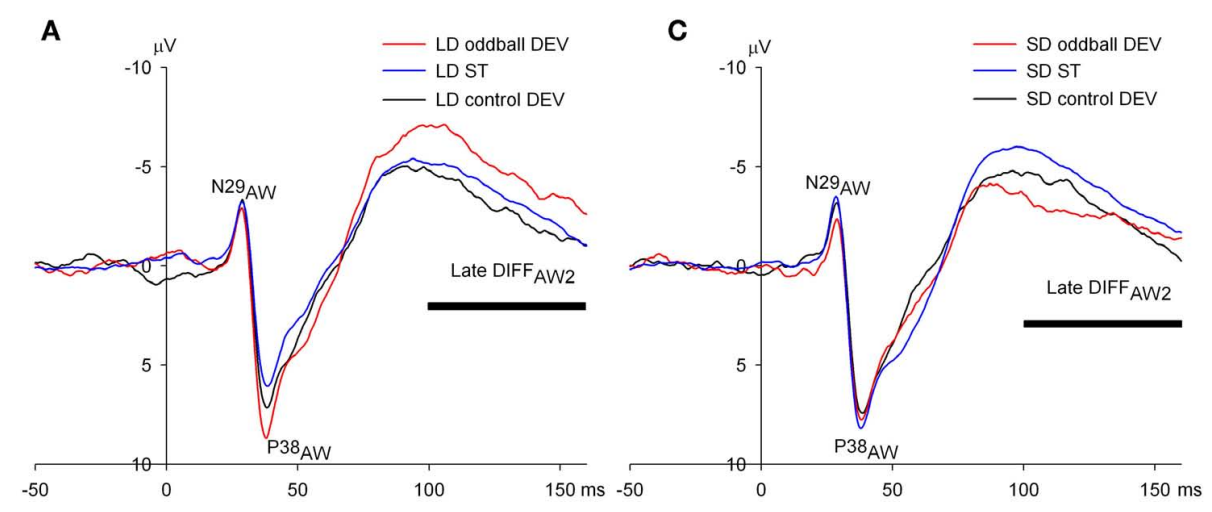

8
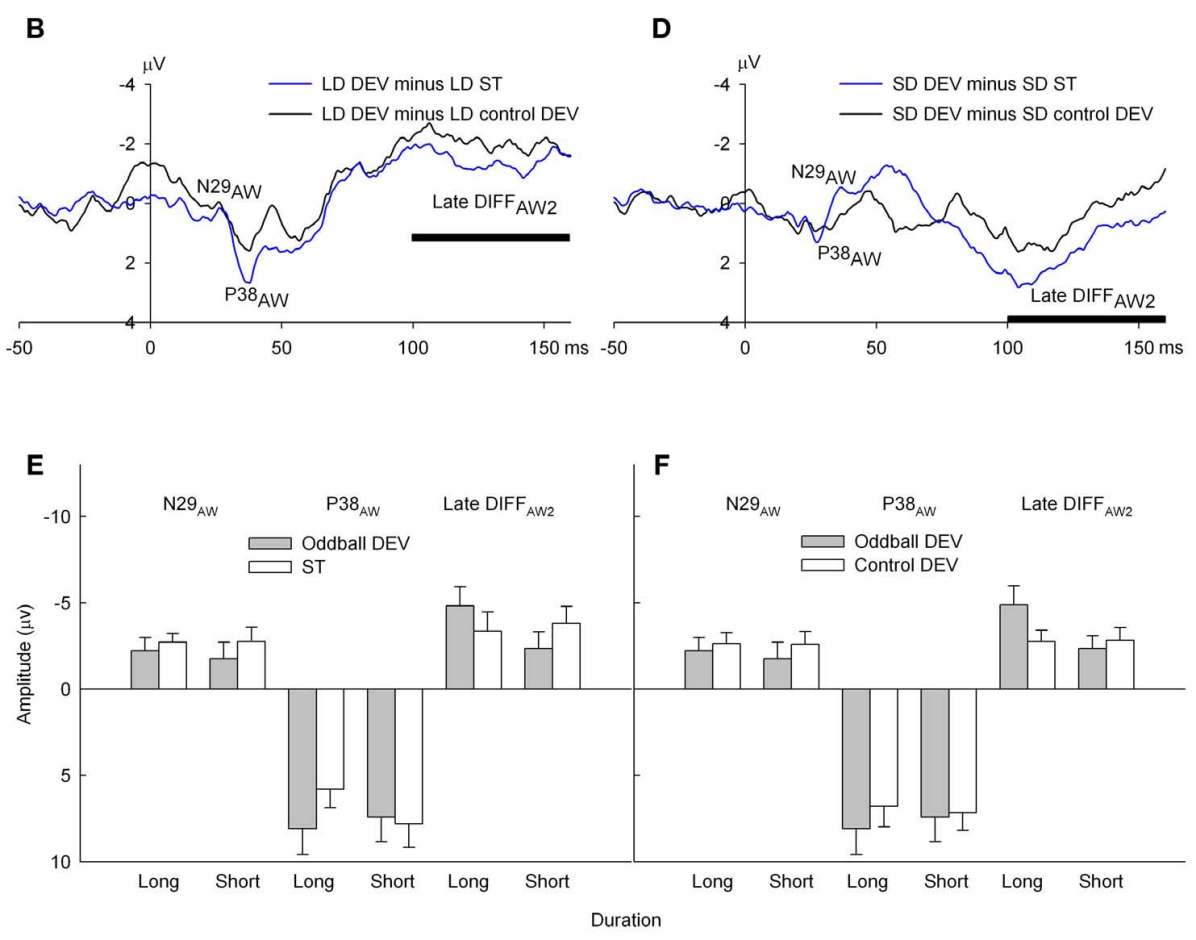

FIGURE 6 | Epidural recorded ERPs in the awake rat to oddball deviant (oddball DEV), standard (ST), and control deviant (control DEV) in the duration conditions. (A) ERPs to long duration (LD) stimuli (150 ms) showing $\mathrm{N}^{2} 9_{\mathrm{AW}}, \mathrm{P} 38_{\mathrm{AW}}$, and late DIFF $\mathrm{AW}_{2}$. LD oddball deviants (red) are negatively displaced over later latencies spanned by late DIFF2 ${ }_{A W 2}$ relative to both LD STs (blue) and LD control DEVs (black). P38 however is also larger to the oddball DEV, a problematic observation since the earliest the auditory system can detect that the DEV is longer is $50 \mathrm{~ms}$ (the duration of short standards in the LD DEV/SD ST oddball sequence). The horizontal bar indicates the latency window over which late $\mathrm{DIFF}_{\mathrm{AW} 2}$ was measured. (B) MMN difference waves for LD stimuli: LD oddball DEV minus LD ST (blue), which can reflect both deviance detection and adaptation effects vs. difference waves derived using control deviants, LD oddball minus LD control DEV (black), which reflects deviance detection. (C) ERPs to short duration (SD) stimuli: N29 $9_{A W}$ and P38 ${ }_{A W}$ show no differences between the oddball DEV ERP (red) relative to the SD ST (blue) and relative to the control DEV (black). Over late latencies spanning late $D_{I F F} F_{\text {AW2 }}$, the SD oddball DEV shows the opposite pattern to LD oddball DEVs in being positively displaced relative to SD ST and SD control DEV but not significantly so. Note that there is no evidence of the P38 effect evident to LD stimuli. (D) MMN difference waves for SD stimuli: SD oddball DEV minus SD ST (blue), and difference waves derived using control deviants, SD oddball DEV minus SD control DEV (black). (E) The mean amplitude (with SE) of $\mathrm{N} 9_{\mathrm{AW}}, \mathrm{P} 38_{\mathrm{AW}}$, and late DIFF $\mathrm{AW}_{2}$ measures generated by long and short duration oddball DEVs (gray) and STs (white). (F) The mean amplitude (with $\mathrm{SE}$ ) of $\mathrm{N}^{2} \mathrm{~S}_{\mathrm{AW}}, \mathrm{P}_{\mathrm{AW}}$, and late $\mathrm{DIFF}_{\mathrm{AW} 2}$ measures generated by long and short duration oddball DEVs (gray) and control DEVs (white).
(100-130 and 130-160 ms) produced similar results), stimulus duration, and the interaction of stimulus duration $\times$ type either approached significance or were significant for both contrasts [oddball DEV vs. ST: duration $F(1,6)=4.40, p=0.081$; interaction $F(1,6)=4.72, p=0.073$ : oddball DEV vs. control DEV: duration $F(1,6)=9.12, p=0.023$; interaction $F(1,6)=5.92$, $p=0.022]$. The duration main effects were due to LD stimuli on average being more negative over this latency range relative to SD stimuli for both contrasts but more robustly so for the oddball DEV vs. control DEV contrast. Simple effects contrasts revealed 
that $\mathrm{DIFF}_{\mathrm{AW}}$ to the LD oddball DEV was significantly more negative than the LD control DEV (oddball DEV vs. control DEV: $t(6)=-2.63, p=0.039)$. Equivalent simple effect contrasts for SD stimuli were not significant (Figure 6F). That is, LD oddball DEV ERPs (but not SD DEV ERPs) exhibited deviance detection in a late window extending from 100 to $160 \mathrm{~ms}$. However, there was no evidence that this late negativity was sensitive to short-term stimulus history of background regularity as it did not show any systematic relationship with the number of preceding standard sounds. Therefore, evidence of MMN-like activity in ERPs to LD oddball deviants is not as strong as for HF oddball deviants.

We now turn to the results for $\mathrm{P} 38_{\mathrm{AW}}$ in the contrast between LD oddball DEV and LD ST. For both Duration MMN paradigms, P38 $8_{\text {AW }}$ occurs before the offset of the shortest tone (i.e., $50 \mathrm{~ms}$ ). It was expected therefore that P38 $8_{\mathrm{AW}}$ would be unaffected in both stimulus type contrasts. This however might not be the case if DEV and ST stimuli are presented in different contexts which indeed they are: LD DEVs are recorded in the ascending deviant oddball sequence whereas LD STs are recorded in the descending deviant oddball sequence. Therefore, we need to look more closely at DEV and ST ERPs from the same oddball sequence. For the LD DEV (150 ms) and SD ST (50 ms) from the same ascending DEV oddball sequence, the stimuli are presented pseudo randomly within the same block, and we see no difference in $\mathrm{P} 38_{\mathrm{AW}}$ amplitude between these stimuli as expected (Figure 7A; $p>0.05)$. For the SD DEV vs. LD ST comparison from the reverse-standard-deviant oddball sequence, again the stimuli are presented pseudo randomly within the same block. Figure 7B suggests a difference in $\mathrm{P} 38_{\mathrm{AW}}$ amplitude, but it is not statistically significant $(p=0.20)$. The problem arises when we compare the LD DEV to the LD ST. These stimuli are physically identical but are presented within different contexts (Figure 7C). The P38 3 AW to the LD ST is considerably smaller than that to the $\operatorname{LD} \operatorname{DEV}(p=0.007)$. This difference is apparent in all seven rats. If we compare the SD DEV to the SD SD, then the problem is not so apparent and the difference is not significant although the amplitude of $\mathrm{P} 38_{\mathrm{AW}}$ measured relative to the preceding $\mathrm{N} 29_{\mathrm{AW}}$ is clearly reduced (Figure 7D). The implications are that $\mathrm{P} 38_{\mathrm{AW}}$ to both DEV and ST is consistently smaller during the LD ST/SD DEV oddball sequence than in the SD ST/LD DEV sequence. This conclusion is supported by the outcome of a two-way repeated
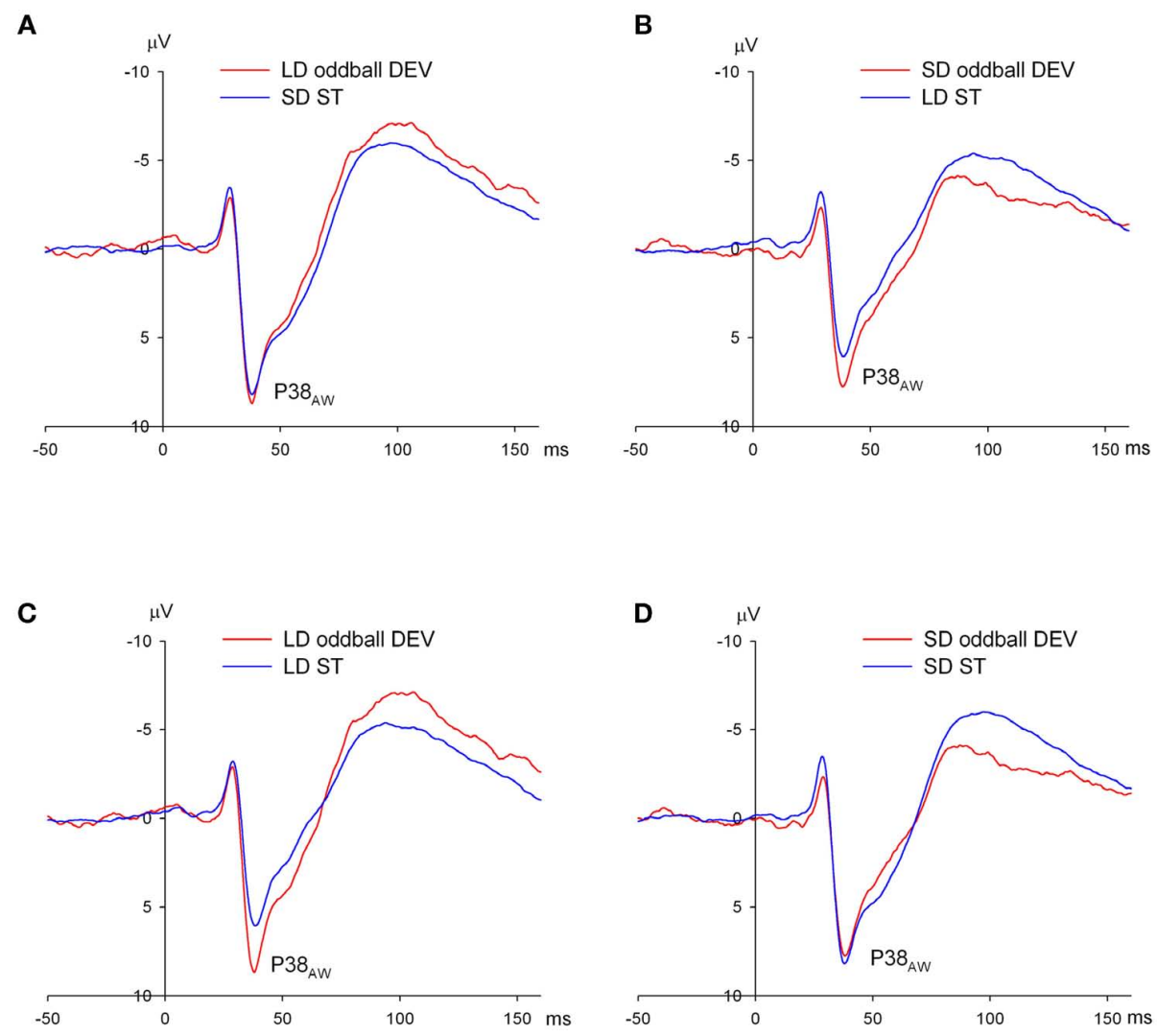

FIGURE 7 | Exploration of the P38 effect evident in long duration (LD) deviants (DEV) relative to LD standards (ST) in the awake rat. (A) ERPs to DEV and ST from the ascending duration oddball sequence: LD oddball DEV (red) and SD ST (blue) showing no difference in P38. (B) ERPs to DEV and ST from the descending duration oddball sequence: SD oddball DEV (red) and LD ST (blue). Note that P38 amplitude is smaller overall in the descending duration oddball sequence with long standards compared with the ascending

duration oddball sequence with short standards shown in (A). (C,D) ERPs to oddball DEVs and STs in the duration oddball paradigms but controlling for stimulus duration: LD stimuli on the left (C) and SD stimuli on the right (D). Oddball DEVs in red and STs in blue. (C,D) are equivalent to Figures $\mathbf{6 A , C}$ respectively without control deviants. The reduced P38 to LD STs from the descending duration oddball sequence is particularly marked in (C), but is less marked for the SD oddball DEV from the same sequence in (D). 
measures ANOVA on P38 $8_{\mathrm{AW}}$ amplitude with factors of oddball sequence (SD DEV/LD ST vs. LD DEV/SD ST) and stimulus type (DEV vs. ST). There is a significant effect of oddball sequence $[F(1$, $6)=7.25, p=0.036$ ] but no main effect of stimulus type and no interaction effect. We believe that these results indicate remarkable sensitivity of $\mathrm{P} 38_{\mathrm{AW}}$ to the predominant stimulus duration in oddball sequences - either (1) because of adaptation effects that are different for long and short stimuli or due to (2) the interstimulus interval before the deviant which is always $350 \mathrm{~ms}$ for the short DEV/long ST oddball sequence and $450 \mathrm{~ms}$ for the long $\mathrm{DEV} /$ short ST oddball sequence or (3) the duration of the preceding stimulus to the deviant which is always $150 \mathrm{~ms}$ for the short DEV/long ST oddball sequence and $50 \mathrm{~ms}$ for the long DEV/short ST oddball sequence.

\section{EPIDURAL ERPS TO ODDBALL DEVIANTS IN ANESTHETIZED RATS}

Despite the relatively noisy recordings and considerable instability in pre-stimulus intervals, ERPs recorded under anesthesia for the four oddball DEVs (HF, LF, LD, and SD) showed consistent displacements relative to their respective STs and control DEV ERPs. In each instance, the oddball DEV ERP exhibited a prolonged positive displacement relative to ST and control DEV ERPs (Figures 8A-D) with an onset latency prior to N67 ${ }_{\mathrm{AN}}$ and persisted until approximately $120 \mathrm{~ms}$ post-stimulus (see Figure $\mathbf{8 E}$ for average over all four stimulus types: HF, LF, LD, and SD). These effects are superimposed on offset potentials evident in most waveforms. Therefore, the same measurement windows were used for all four oddball DEV conditions: N67 $\mathrm{AN}$ and two later windows spanning 70-100 and 100-130 ms, which will be referred to here as late DIFF $_{\mathrm{AN} 1}$ and late DIFF $\mathrm{AN} 2$. Each of these measures was analyzed using ANOVAs with two repeated measures factors, deviant type with four levels (HF, LF, LD, and SD) and stimulus type with two levels (oddball DEV vs. ST or oddball DEV vs. control DEV).

There were no significant main effects or interactions involving deviant type on any ERP measure indicative of the insensitivity of onset ERPs under anesthesia to stimulus parameters. However, the oddball DEV exhibited a significant positive displacement relative to the ST over both $\mathrm{N} 7_{\mathrm{AN}}[F(1,6)=7.25, p=0.036]$ and the late $\operatorname{DIFF}_{\mathrm{AN} 1}[F(1,6)=7.01, p=0.038$; Figure 8F $]$. Both measures showed a similar pattern when the oddball DEV was compared to the control DEV $\left[\mathrm{N}_{67} \mathrm{AN}: F(1,6)=6.29, p=0.046\right.$; late DIFF $\mathrm{AN}_{1}$ : $F(1,6)=5.78, p=0.053$; Figure 8F]. Neither contrast was significant over the later interval (late $\mathrm{DIFF}_{\mathrm{AN} 2}$ ). Although these results should be treated cautiously given the data quality, they nonetheless suggest that in the anesthetized animal, MMN-like potentials take the form of a positive displacement of the deviant ERP.

\section{DISCUSSION}

This study sought evidence of MMN-like activity in epidural potentials in awake and anesthetized rats to HF and LF and LD and SD deviant sounds. In order to determine whether MMN-like activity reflects deviance detection relative to background regularity or differential adaptation due to the rarity of deviants, epidural ERPs to deviant oddball sounds were compared not only with ERPs to a common standard with the same physical features to the deviant but also with ERPs to the same tone as the manystandards control deviant. The main findings were: (a) epidural
ERPs in the awake animal showed evidence of deviance detection to both HF and LD deviants. MMN-like activity was evident as negative displacements of the oddball deviant ERP relative to ERPs to a common standard and a deviant with many standards. (b) The awake MMN-like response to HF deviants was also sensitive to local temporal context of preceding stimulus regularity: it increased with the number of preceding standards prior to the deviant sound. The MMN-like response to LD deviants was not sensitive to local stimulus history. (c) LF deviants and SD deviants did not elicit consistent MMN-like responses in the awake rat. (d) Anesthesia resulted in positive displacements of the oddball deviant ERP relative to ERPs to the standard with the same physical features and the many-standards control deviant, that is, a polarity reversal of the MMN-like responses seen in the awake rat.

\section{THE EFFECTS OF DEVIANT FEATURES ON EPIDURAL ERP COMPONENTS AND MMN-LIKE RESPONSES}

Previous reports utilizing epidural recordings in the rat also claim to have found evidence of MMN-like activity to simple invariance frequency and duration deviants (Table 1). We used frequencies similar to the 2000 - and $2500-\mathrm{Hz}$ stimuli used in the Tikhonravov et al. $(2008,2010)$ reports and therefore the lack of MMN to LF deviants might appear inconsistent with these reports, but neither analyzed LF and HF deviants separately. The lack of MMNlike activity to LF deviants in our data could be attributed to the $2500-\mathrm{Hz}$ tone being less than optimal for the Wistar rat. This was evident in the smaller amplitude of two major ERPs components, $\mathrm{N} 29$ and N90, to any tone burst of $3000 \mathrm{~Hz}$ or less in the manystandards frequency control sequence (see Figures 2A,B) and is consistent with limited data available on the rat frequency audiogram (Jamison, 1951; Gourevitch, 1965; Mazurek et al., 2010). However, Astikainen et al. (2011) have also recently reported MMN-like responses to ascending (high) frequency deviants but not to descending (low) deviants. The authors draw attention to similar asymmetries in MMN (Peter et al., 2010) and auditory discrimination thresholds (Kishon-Rabin et al., 2004) in humans.

Our duration deviant data are comparable, in one respect, with the only published paper reporting duration MMN data in rats (Roger et al., 2009) in that MMN-like activity appeared as a negative displacement of deviant relative to the standard ERP, although in our study only the LD deviant showed significant evidence of an MMN-like response. However, some caution is warranted in interpreting these data as evidence of MMN-like activity, since the late negative displacements in deviant ERPs were insensitive to the degree of preceding stimulus regularity. We were unable to replicate the Roger et al. (2009) duration decrement findings despite the design of our duration decrement oddball sequence being similar to the condition which elicited the largest MMN-like response in Roger et al. (2009). However, the asymmetric findings in our data once again have parallels in the human MMN and auditory perception literature. MMN to duration decrements are smaller than duration increments (Catts et al., 1995), even with equivalent physical differences between deviants and standards. Analogous asymmetries have also have been observed in psychoacoustical studies in humans (Cusack and Carlyon, 2003). 


\section{A}

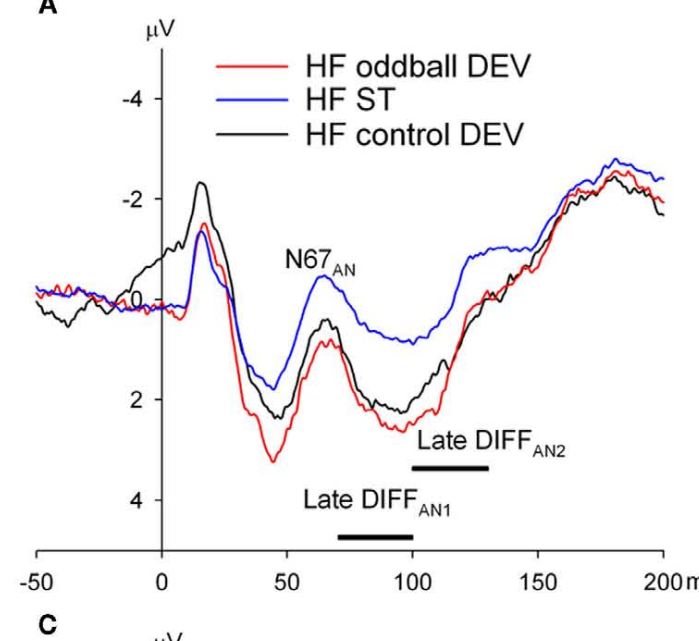

c

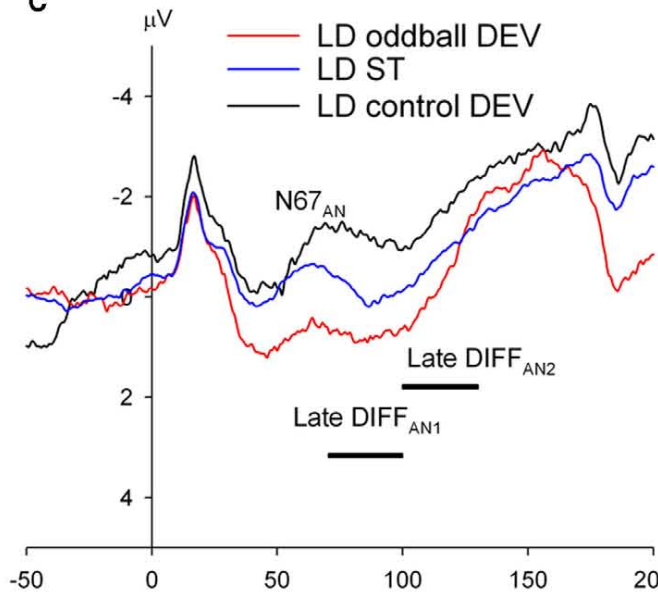

D
B
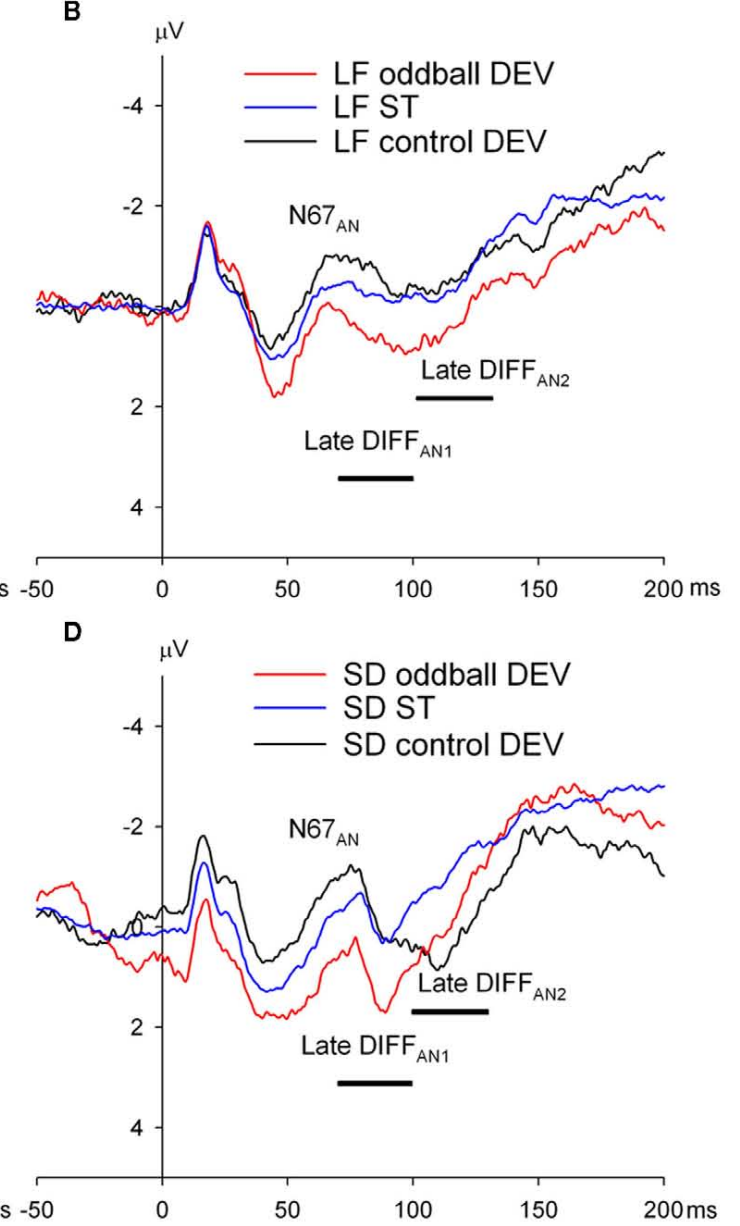

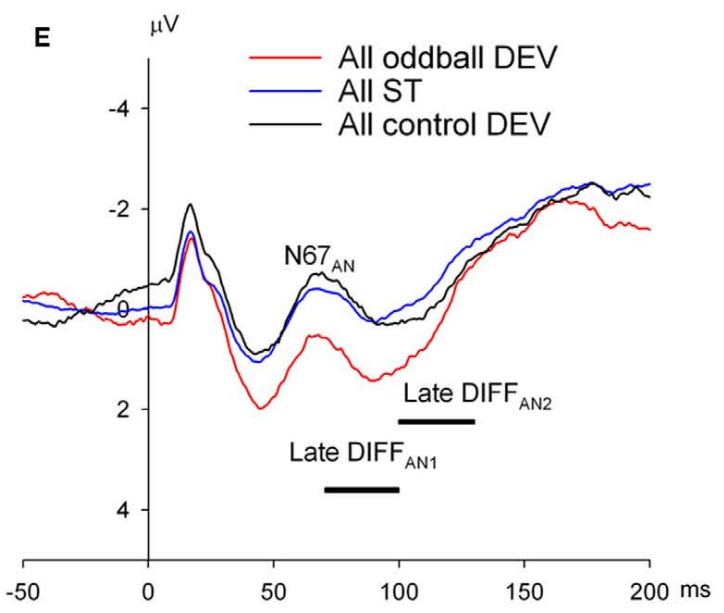

$-50$
FIGURE 8 | Epidural recorded ERPs in the anesthetized rat to oddball deviant (oddball DEV), standard (ST) and control deviant (control DEV) for both the frequency and duration oddball sequences. (A,B) ERPs to oddball DEV (red), ST (blue), and control DEV (black) for high frequency (HF) and low frequency (LF) stimuli respectively. (C,D) ERPs to oddball DEV (red), ST (blue), and control DEV (black) for long duration (LD) and short duration (SD) stimuli respectively. All four stimuli show a similar pattern (unlike the awake state): oddball

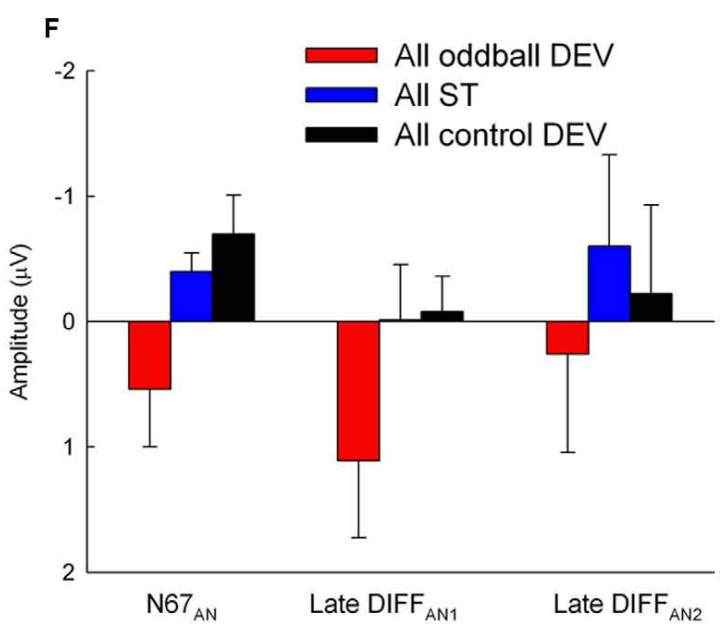

DEVs show a positive shift relative to STs and control DEVs. (E) ERPs obtained by averaging over all stimulus conditions to produce averaged oddball DEV, ST, and control DEV ERPs providing a depiction of the positive displacement of oddball DEVs relative to STs and control DEVs. (F) Mean amplitudes (with SEs) of $\mathrm{N} 7_{\mathrm{AN}}$, late DIFF $\mathrm{AN}_{1}$ and late DIFF generated by oddball DEVs (red), STs (blue) and control DEVs (black) showing that $\mathrm{N} 67_{\mathrm{AN}}$ and late DIFF $\mathrm{AN}_{\mathrm{A} 1}$ are both more positive than STs $(p=0.046)$ and control DEVs $(p=0.053)$. 


\section{DEVIANCE DETECTION IN RAT EPIDURAL RECORDINGS: THE OPTIMAL CONTROL CONDITION}

As noted in the introduction, previous reports of MMN-like activity reflecting deviance detection in rat epidural potentials (Ruusuvirta et al., 1998; Tikhonravov et al., 2008, 2010) used a control condition in which the deviant alone was presented without standards at the same interstimulus interval as the oddball sequence. The rationale is that if the MMN-like activity is not present in the deviant-alone ERP, the MMN-like activity in the oddball deviant cannot be attributed to differences in adaptation, but is reliant on the presence of stimulus regularity established by the presence of standards. However, auditory cortex neurons have complex temporal dynamics, so that stimulus sequences that differ with respect to interstimulus intervals may engage very different mechanisms (Nelken and Ulanovsky, 2007). Consensus is emerging that the deviant with many different standards paradigm is the best control for differential adaptation effects, stimulus features and background context regularity (Nelken and Ulanovsky, 2007). Our data demonstrate that epidural potentials show evidence of deviance detection in the awake rat using this control for the HF deviant and for the LD deviant, and in the anesthetized rat when averaged over the four deviants (HF, LF, LD, and SD). Interestingly, our data also show that in general there were only minor differences between MMN-like activity extracted using the many-standards control vs. the common standard (with the same physical attributes as the deviant). Evidence of deviance detection has also recently been reported in epidural potentials of anesthetized rats using the many-standards control (Astikainen et al., 2011). Further, Taaseh et al. (2011) concluded that there was evidence of deviance detection in MUA and eLFP responses of anesthetized rats based on data showing that observed MUA and eLFP responses to the deviant were larger than predicted responses derived from a model of SSA that included only adaptation of responses in narrow frequency channels. In contrast, other studies using MUA and eLFP recordings in rat AC concluded that there was no evidence for deviance detection (von der Behrens et al., 2009; Farley et al., 2010). These inconsistencies may be due to a variety of methodological differences between the respective studies.

Some caveats are necessary in relation to the design of the manystandards control. In the control sequence there were five different tones. If the control DEV was positioned as either the upper or lower extreme within this set, then it is possible that they may be perceived as deviant compared to the non-extreme stimuli. This extreme sub-standard effect has been noted, particularly for duration (Jacobsen and Schröger, 2003). To avoid this possibility, in this study, the equivalent of the frequency deviants (HF and LF) were positioned either side of the middle frequency in the range such that there was an intervening frequency between them (see Figure 1A). The problem with this design is that it is possible that the smaller N29 in the HF control deviant (Figure 4A) could be accounted for by greater adaptation of exogenous N29 generators caused by partly overlapping frequency-specific neural populations responding to tones adjacent to HF. However, it is unlikely that similar caveats apply to the later negativities, $\mathrm{Nd} 42_{\mathrm{AW}}$ and the late DIFFAW1 - they appear to be a separate non-exogenous components associated with deviance detection and in the case of
$\mathrm{Nd} 42_{\mathrm{AW}}$ in particular, behave similarly to the human MMN [i.e., the ERPs to the oddball deviant is more negative than the ERPs to the control deviant (Figure $4 \mathbf{F}$ ) and the amplitude of the negative displacement is sensitive to the local probability of the oddball deviant (Figure 5C)].

\section{ANESTHESIA EFFECTS}

Anesthesia resulted in a polarity reversal of MMN-like potentials, that is, a positive displacement, a finding that is consistent with most previous findings in anesthetized rats except for Ruusuvirta et al. (2007) and Eriksson and Villa, 2005; see Table 1). Previously, $\mathrm{N}$-methyl-D-aspartate receptor antagonists have been suggested to affect MMN-like activity in animals (Javitt et al., 1996; Tikhonravov et al., 2008, 2010) and the absence of MMN-like activity in the anesthetized rats in Eriksson and Villa (2005) may be due to the use of ketamine. In the current study, anesthesia also resulted in marked reductions in ERP component amplitudes to tone bursts, a loss of frequency sensitivity of ERP component amplitudes in the frequency control sequence and the appearance of offset potentials in the duration control sequence which were essentially absent in the awake state. In general, the activity of AC neurons tends to be reduced by general anesthetics and characterized by more phasic responses and reduced sustained firing relative to the awake state (Zurita et al., 1994). Barbiturates in particular may both depress excitation and enhance inhibition (Pocock and Richards, 1993). However, the extent and nature of the effect on AC neurons varies with different anesthetics (Moshitch et al., 2006). There are no data to our knowledge on the combined effect of two anesthetics used in this report, fentanyl, a mu-opioid receptor agonist, and medetomidine, a selective alpha 2 adrenoceptor. The presence of offset responses under anesthesia in our data point to potentiation of inhibition as larger offset responses in the rat are associated with greater inhibitory rebound following cessation of a stimulus (Takahashi et al., 2004). Alterations in the relative balance of excitation and inhibition under anesthesia (Wehr and Zador, 2003; Rennaker et al., 2007) may also explain not only the loss of sensitivity of early ERP components to tone burst frequency but also the polarity reversal of MMN-like response. In humans, widespread cortical surface negativities have been associated with cortical excitability (Birbaumer et al., 1990), whereas cortical surface positivities are associated with cortical disfacilitation or inhibition (Shupp et al., 1994). Further research is required to understand the cortical circuitry producing either negative or positive displacements.

\section{IMPLICATIONS FOR FUTURE TRANSLATIONAL RESEARCH}

Although it has been claimed in the past that MMN potentials in humans and rodents are homologous (Bickel and Javitt, 2009), such a claim could be seen as premature as attempts to demonstrate a deviance detection $\mathrm{MMN}$ in rats to date have resulted in patterns that have been portrayed as "weak or ambiguous" (von der Behrens et al., 2009, p. 13837). However, if the effects observed here for HF deviants are replicated with an improved design, it becomes feasible to exploit MMN as an endophenotype in translational research aimed at testing a range of animal models of schizophrenia, and to assess the likely efficacy of new compounds (Luck et al., 2011). 


\section{ACKNOWLEDGMENTS}

This study was supported by the Schizophrenia Research Institute utilizing infrastructure funding from NSW Health, the University of Newcastle Research Grants committee, the Hunter Medical

\section{REFERENCES}

Astikainen, P., Ruusuvirta, T., Wikgren, J., and Penttonen, M. (2006). Memory-based detection of rare sound feature combinations in anesthetized rats. Neuroreport 17, 1561-1564.

Astikainen, P., Stefanics, G., Nokia, M., Lipponen, A., Cong, F., Penttonen, M., and Ruusuvirta, T. (2011). Memory-based mismatch response to frequency changes in rats. PLoS ONE 6, e24208. doi:10.1371/journal.pone.0024208

Bickel, S., and Javitt, D. (2009). Neurophysiological and neurochemical animal models of schizophrenia: focus on glutamate. Behav. Brain Res. 204, 352-362.

Birbaumer, N., Elbert, T., Canavan, A., and Rockstroh, B. (1990). Slow potentials of the cerebral cortex and behavior. Physiol. Rev. 70, 1-41.

Catts, S., Shelley, A., Ward, P., Liebert, B., McConaghy, N., Andrews, S., and Michie, P. (1995). Brain potential evidence for an auditory sensory memory deficit in schizophrenia. Am. J. Psychiatry 152, 213-219.

Cox, E., Langemeijer, M., GubbensStibbe, J., Muir, K., and Danhof, M. (1999). The comparative pharmacodynamics of remifentanil and its metabolite, GR90291, in a rat electroencephalographic model. Anesthesiology 90, 535-544.

Cusack, R., and Carlyon, R. (2003). Perceptual asymmetries in audition. $J$. Exp. Psychol. Hum. Percept. Perform. 29, 713-725.

Eriksson, J., and Villa, A. E. (2005). Event-related potentials in an auditory oddball situation in the rat. BioSystems 79, 207-212.

Farley, B., Quirk, M., Doherty, J., and Christian, E. (2010). Stimulusspecific adaptation in auditory cortex is an NMDA-independent process distinct from sensory novelty encoded by mismatch negativity. J. Neurosci. 30, 16475-16484.

Fulham, W. R. (2009). EEG Display, 6.1.5 Edn. Newcastle NSW: The University of Newcastle.

Garagnani, M., and Pulvermüller, F. (2011). From sounds to words: a neurocomputational model of adaptation, inhibition and memory processes in auditory change detection. Neuroimage 54, 170-181.
Garrido, M., Kilner, J., Stephan, K., and Friston, K. (2009). The mismatch negativity: a review of underlying mechanisms. Clin. Neurophysiol. 120, 453-463.

Gourevitch, G. (1965). Auditory masking in the rat. J. Acoust. Soc. Am. 37, 439-443.

Haberham, Z., Van De Brom, W., Haagen, A., De Groof, H., Baumans, V., and Hellebrekers, L. (2000). "Differential monitoring of hypnosis and anti-nociception during fentanyl anaesthesia using spontaneous and evoked electroencephalography in the rat," in Development and Evaluation of Methods for Assessment of Quality of Anaesthesia in the Rat, ed. Z. Haberham (Utrecht: University of Utrecht), 77-101.

Jääskeläinen, I., Ahveninen, J., Bonmassar, G., Dale, A., Ilmoniemi, R., Levänen, S., Lin, F., May, P., Melcher, J., Stufflebeam, S., Tiitinen, H., and Belliveau, J. (2004). Human posterior auditory cortex gates novel sounds to consciousness. Proc. Natl. Acad. Sci. U.S.A. 101, 6809-6814.

Jacobsen, T., and Schröger, E. (2001). Is there pre-attentive memory-based comparison of pitch? Psychophysiology 38, 723-727.

Jacobsen, T., and Schröger, E. (2003). Measuring duration mismatch negativity. Clin. Neurophysiol. 114, 1133-1143. T., and Winkler, I. (2003). Mismatch negativity to pitch change: varied stimulus proportions in controlling effects of neural refractoriness on human auditory event-related potentials. Neurosci. Lett.334, 79-82.

Jamison, J. H. (1951). Measurement of auditory intensity thresholds in the rat by conditioning of an autonomic response. J. Comp. Physiol. Psychol. 44, 118-125.

Javitt, D. C., Steinschneider, M., Schroeder, C. E., and Arezzo, J. C. $\mathrm{D}$-aspartate receptors in auditory sensory memory and mismatch negativity generation: implications for schizophrenia. Proc. Natl. Acad. Sci. U.S.A. 93, 11962-11967.

Kishon-Rabin, L., Roth, D., Van Dijk, B., Yinon, T., and Amir, O. (2004). Frequency discrimination thresholds: ment detection of frequency. J. Basic Clin. Physiol. Pharmacol. 15, 29-40.
Jacobsen, T., Schröger, E., Horenkamp, (1996). Role of cortical N-methylthe effect of increment versus decre-

Research Institute, the Centre for Brain and Mental Health Research and the School of Psychology, The University of Newcastle. We thank Tony Kemp and Gavin Cooper for technical assistance.

Lazar, R., and Metherate, R. (2003). Spectral interactions, but no mismatch negativity, in auditory cortex of anesthetized rat. Hear. Res. 181, 51-56.

Luck, S., Mathalon, D., O’Donnell, B., Hämäläinen, M., Spence, K. Javitt, D., and Uhlhass, P. (2011). A roadmap for the development and validation of event-related potential biomarkers in schizophrenia research. Biol. Psychiatry 70, 28-34.

Maess, B., Jacobsen, T., Schröger, E., and Friederici, A. D. (2007). Localizing pre-attentive auditory memory-based comparison: magnetic mismatch negativity to pitch change. Neuroimage 37, 561-571.

May, P., and Tiitinen, H. (2010). Mismatch negativity (MMN), the deviance-elicited auditory deflection, explained. Psychophysiology 47, 66-122.

May, P., Tiitinen, H., Ilmoniemi, R. Nyman, G., Taylor, J., and Näätänen, R. (1999). Frequency change detection in human auditory cortex. $J$. Comput. Neurosci. 6, 99-120.

Mazurek, B., Haupt, H., Joachim, R. Klapp, B., Stover, T., and Szczepek, A. (2010). Stress induces transient auditory hypersensitivity in rats. Hear. Res. 259, 55-63.

Michie, P. T. (2001). What has MMN revealed about the auditory system in schizophrenia? Int. J. Psychophysiol. 42, 83-100.

Moshitch, D., Las, L., Ulanovsky, N. Bar-Yosef, O., and Nelken, I. (2006). Responses of neurons in primary auditory cortex $(\mathrm{A} 1)$ to pure tones in the halothane-anesthetized cat. $J$. Neurophysiol. 95, 3756-3769.

Näätänen, R. (1990). The role of attention in auditory information processing as revealed by event-related potentials and other brain measures of cognitive function. Behav. Brain Sci. 13, 201-288.

Näätänen, R. (1992). Attention and Brain Function. Hillsdale, NJ: Erlbaum.

Näätänen, R., Jacobsen, T., and Winkler I. (2005). Memory-based or afferent processes in mismatch negativity (MMN): a review of the evidence. Psychophysiology 42, 25-32.

Nelken, I., and Ulanovsky, N. (2007). Mismatch negativity and stimulus specific adaptation in animal models. J. Psychophysiol. 21, 214-223.
Peter, V., McArthur, G., and Thompson, W. (2010). Effect of deviance direction and calculation method on duration and frequency mismatch negativity (MMN). Neurosci. Lett. 482, 71-75.

Picton, T., Alain, C., Otten, L., Ritter, W., and Achim, A. (2000). Mismatch negativity: different water in the same river. Audiol. Neurootol. 5, 111-139.

Pocock, G., and Richards, C. (1993). Excitatory and inhibitory synaptic mechanisms in anaesthesia. Br. J. Anaesth. 71, 134-147.

Rennaker, R., Carey, H., Anderson, S., Sloan, A., and Kilgard, M. (2007). Anesthesia suppresses nonsynchronous responses to repetitive broadband stimuli. Neuroscience 145, 357-369.

Roger, C., Hasbroucq, T., Rabat, A., Vidal, F., and Burle, B. (2009). Neurophysics of temporal discrimination in the rat: a mismatch negativity study. Psychophysiology 46, 1028-1032.

Ruusuvirta, T., Koivisto, K., Wikgren, J. and Astikainen, P. (2007). Processing of melodic contours in urethaneanaesthetised rats. Eur. J. Neurosci. 26, 701-703.

Ruusuvirta, T., Penttonen, M., and Korhonen, T. (1998). Auditory cortical event-related potentials to pitch deviances in rats. Neurosci. Lett. 248, 45-48.

Shupp, H., Lutzenberger, W., Ray, H., and Birbaumer, N. (1994). Positive shifts of event-related potentials: a state of cortical disfacilitation as reflected by the startle reflex probe. Electroencephalogr. Clin. Neurophysiol. 90, 135-144.

Taaseh, N., Yaron, A., and Nelken, I. (2011). Stimulus-specific adaptation and deviance detection in the rat auditory cortex. PLoS ONE 6, e23369. doi:10.1371/journal.pone.0023369

Takahashi, H., Nakao, M., and Kaga, K. (2004). Cortical mapping of auditory-evoked offset responses in rats. Neuroreport 15, 1565-1569.

Tikhonravov, D., Neuvonen, T., Pertovaara, A., Savioja, K., Ruusuvirta, T., Näätänen, R., and Carlson, S. (2008). Effects of an NMDAreceptor antagonist $\mathrm{MK}-801$ on an MMN-like response recorded in anesthetized rats. Brain Res. 1203 , 97-102. 
Tikhonravov, D., Neuvonen, T., Pertovaara, A., Savioja, K., Ruusuvirta, T., Näätänen, R., and Carlson, S. (2010). Dose-related effects of memantine on a mismatch negativity-like response in anesthetized rats. Neuroscience 167, 1175-1782.

Ulanovsky, N., Las, L., Farkas, D., and Nelken, I. (2003). Multiple time scales of adapation in auditory cortex neurons. J. Neurosci. 24, 10440-10453.

Umbricht, D., and Krljes, S. (2005). Mismatch negativity in schizophrenia: a meta-analysis. Schizophr. Res. 76, $1-23$.

von der Behrens, W., Bäuerl, P., Kössl, M., and Gaese, B. (2009). Correlating stimulus-specific adaptation of cortical neurons and local field potentials in the awake rat. $\mathrm{J}$. Neurosci. 29, 13837-13849.

Wehr, M., and Zador, A. (2003). Balanced inhibition underlies tuning and sharpens spike timing in auditory cortex. Nature 426, 442-446.

Winkler, I. (2007). Interpreting the mismatch negativity. J. Psychophysiol. 21, 147-163.

Winkler, I., Karmos, G., and Näätänen, R. (1996). Adaptive modeling of the unattended acoustic environment reflected in the mismatch negativity event-related potential. Brain Res. 742, 239-252.

Winkler, I., Paavilainen, P., Alho, K., Reinikainen, K., Sams, M., and Näätänen, R. (1990). The effect of small variation of the frequent auditory stimulus on the event-related brain potential to the infrequent stimulus. Psychophysiology 27, 228-235.

Zurita, P., Villa, A., De Ribaupierre, Y., De Ribaupierre, F., and Rouiller, E. (1994). Changes of single unit activity in the cat's auditory thalamus and cortex associated to different anesthetic conditions. Neurosci. Res. 19, 303-316.

Conflict of Interest Statement: The authors declare that the research was conducted in the absence of any commercial or financial relationships that could be construed as a potential conflict of interest.

Received: 16 June 2011; accepted: 22 November 2011; published online: 09 December 2011.
Citation: Nakamura T, Michie PT, Fulham WR, Todd J, Budd TW, Schall U, Hunter $M$ and Hodgson DM (2011) Epidural auditory event-related potentials in the rat to frequency and duration deviants: evidence of mismatch negativity? Front. Psychology 2:367. doi: 10.3389/fpsyg.2011.00367

This article was submitted to Frontiers in Auditory Cognitive Neuroscience, a specialty of Frontiers in Psychology.

Copyright (c) 2011 Nakamura, Michie, Fulham, Todd, Budd, Schall, Hunter and Hodgson. This is an open-access article distributed under the terms of the Creative Commons Attribution Non Commercial License, which permits non-commercial use, distribution, and reproduction in other forums, provided the original authors and source are credited. 